\title{
PRICE SETTING UNDER UNCERTAINTY ABOUT INFLATION*
}

\author{
ANDRES DRENIK ${ }^{\dagger}$ \\ Department of Economics \\ Stanford University
}

\author{
DIEGO PEREZ \\ Department of Economics \\ Stanford University
}

October 2, 2014

\begin{abstract}
When setting prices firms use idiosyncratic information about the demand for their products as well as public information about the aggregate macroeconomic state. This paper provides an empirical assessment of the effects of the availability of public information about inflation on price setting. We exploit an event in which economic agents lost access to information about the inflation rate: starting in 2007 the Argentinean government began to misreport the national inflation rate. Our difference-in-difference analysis reveals that this policy led to an increase in the coefficient of variation of prices of $18 \%$ with respect to its mean. This effect is analyzed in the context of a general equilibrium model in which agents make use of publicly available information about the inflation rate to set prices. We quantify the model and use it to further explore the effects of higher uncertainty about inflation on the effectiveness of monetary policy and aggregate welfare. We find that monetary policy becomes more effective in a context of higher uncertainty about inflation and that not reporting accurate measures of the CPI entails significant welfare losses.
\end{abstract}

Keywords: Prices, public information, monetary policy.

First Draft: December 15, 2013.

*We thank Ran Abramitzky, Nick Bloom, Sebastian Di Tella, Pete Klenow, Pablo Kurlat, Pablo Ottonello, Monika Piazzesi, Luigi Pistaferri, Martin Schneider, Chris Tonetti and seminar participants at the Stanford Macro Lunch and Applied Lunch, and Princeton EconCon for valuable comments and suggestions. We also thank the company that provided the data and their employees for their cooperation and help, and also Guido Sandleris for sharing the data on inflation expectations.

$\dagger$ adrenik@stanford.edu.

$\ddagger$ dperez1@stanford.edu. 


\section{INTRODUCTION}

When setting prices firms use idiosyncratic information about their past revenues and costs as well as public information about the aggregate macroeconomic state in order to estimate the current and future demand for their products, their cost function and predict the prices set by other firms. In contexts in which firms are unable to identify the nature of the idiosyncratic and aggregate shocks they face given their set of available information, the availability of credible and precise public information about the aggregate state of the economy will be a key factor in the determination of equilibrium prices and allocations. Additionally, the amount of information that firms have about the aggregate macroeconomic state has important implications for the role of monetary policy (see, for example, Reis (2009)).

Understanding how the availability of public information affect firms' pricing behavior can help us address relevant macroeconomic questions such as, what is the social value of releasing public information about the aggregate macroeconomic state? Given the relevance of this topic an important strand of the theoretical macroeconomics literature has studied the effects of the release of public information not only on price setting but on the general equilibrium of an economy. ${ }^{1}$ However, perhaps due to the difficulty in identifying settings with variations in the availability of public information about the aggregate macroeconomic state, the empirical counterpart to this literature is scarcer.

The aim of this paper is to provide an empirical analysis of the effects of changes in the availability of public information about the aggregate inflation rate on the price setting decisions made by firms and provide a quantitative assessment of how this effect on prices affects the effectiveness of monetary policy and aggregate welfare. To do so, we separate our analysis into two parts. The first part of the paper performs an empirical analysis of the effect of changes in the availability of public information about the inflation rate on observed price dispersion by exploiting an episode in which economic agents lost access to quality public information about the inflation rate and using micro data to estimate its effect on price dispersion. The second part of the paper formulates a general equilibrium model of price setting tailored to analyze our episode and calibrates it to match our empirical findings from the first part. Using our calibrated model, we analyze the effects of higher uncertainty

\footnotetext{
${ }^{1}$ For general effects of information frictions see, for example, Amador and Weill (2010), Angeletos and Pavan (2004), Angeletos and Pavan (2007) and Morris and Shin (2002). For effects on pricing decisions see, for example, Angeletos and La'O (2009), Reis (2006), Alvarez et al. (2011b).
} 
about the aggregate level of inflation on the effectiveness of monetary policy and compute the welfare losses of having poor quality statistics about the aggregate rate of inflation.

Since January 2007 the Argentinean government started misreporting the national inflation rate. It did not take long until private firms and local governments started reporting their own measures of inflation. However, given their limitations in the recollection of data, these different measures exhibit a great deal of variability. Thus, we consider this event as an episode in which agents lost access to accurate aggregate information about the inflation rate and use it to analyze the effect of the availability of public information on price dispersion. This is the first paper that looks at this episode to analyze economic effects of changes in the availability of public information. The empirical analysis consists of a difference-indifference-type estimation where Uruguay serves the purpose of the control group. The choice of the control country is driven by their similar economic characteristics, similar exposure to external macroeconomic shocks, and the high synchronization of their business cycles.

The empirical analysis is carried out with data on prices from the largest e-trade platform in Latin America. We have data on more than 140 million of publications of goods for sale. Using the posted prices of each publication and the categorization of the product we compute the price dispersion (measured as the coefficient of variation of prices) for all product categories for both countries on a quarterly basis for the period 2003-2012. Controlling for observed inflation, we then use a difference-in-difference approach to estimate the effect of the manipulation of official inflation statistics on price dispersion.

Our empirical estimations yield a difference-in-difference coefficient that is positive and significant, indicating that higher uncertainty about the levels of inflation increase observed price dispersion. The effect is also quite large in economics terms. The deterioration in the quality of public information about the levels of inflation in Argentina caused by the manipulation of official inflation statistics led to an increase in the coefficient of variation of prices of $18 \%$ with respect to its mean.

We carry out robustness estimations that dwell with the choice of the dependent variable (other measures of price dispersion), the functional form of the estimation equation and the identification strategy, and we find that results are insensitive to these robustness tests. Additionally, we find that the effect on price dispersion was permanent and it gradually increased over time with a log-shaped effect. We then carry out estimations that differ in how we group products together to compute price dispersion measures. We find that for the estimations with more specific grouping criteria the effect is larger than in estimations 
where we group products more generally. We interpret this result as a differential effect for different degrees of substitutability within products: for a given shock to the information about inflation, the effect on price dispersion is higher, the higher the elasticity of substitution between products.

Having established our main empirical result we then formulate a general equilibrium model of price setting tailored to analyze our episode. In the model firms make use of a noisy publicly-available signal of the aggregate level of prices, together with idiosyncratic information about their revenues and costs to set their prices. Given their information set, firms cannot perfectly tell apart the nature of all the shocks in the economy. The model will display a source of money non-neutrality stemming from informational frictions that goes back to the seminal works of Phelps (1970) and Lucas (1972). This allows the model to give insights about the effectiveness of monetary policy in the context of uncertainty about the aggregate price level. To reproduce the observed policy-change episode in Argentina with our model we change the variance of the noise associated to the signal of aggregate prices and explore its effect on aggregate allocations.

Our model can speak to our empirical findings since an increase in the variance of the noise associated to the signal of aggregate prices increases the cross-sectional price dispersion. The mechanism behind this result is that, faced with a noisier signal of aggregate prices, firms optimally increase the weights attached to their idiosyncratic signals of demand and wages and reduce their weight attached to the aggregate signal when setting their prices. Given that idiosyncratic signals have cross-sectional dispersion and the aggregate signal does not, this translates into higher cross-sectional dispersion of prices. By exploring the transitional dynamics of the change in the variance of the noise in the signal of aggregate prices, the model also helps us understand why we find an effect that increases over time at a decaying rate in our empirical estimations. The optimal short-term reaction of firms to an increase in variance of the noise of signal of aggregate prices is not only to place more weight in their idiosyncratic signals but also to place more weight on past signals of aggregate prices that were not contaminated by the high-variance noise. As time goes by, the latter become less useful as a predictor of current economic shocks and therefore firms shift their weights to current idiosyncratic shocks and thus observed price dispersion increases.

We use panel data on wages for Argentina and moments on aggregate prices to estimate and calibrate the underlying parameters of the model. Additionally, we use our estimated increase in price dispersion to calibrate the implicit increase in the variance of the signal of 
aggregate prices. Our calibrated model is then put to work to analyze the effectiveness of monetary policy in a context in which agents are uncertain about what the aggregate inflation rate is. We find that monetary policy is more effective in the context of higher uncertainty about aggregate prices. In particular, two years after the realization of a monetary shock, prices adjust 30\% less in an economy with a noisy signal of aggregate prices compared to their reaction in an economy with an accurate signal of aggregate prices. This differential reaction of prices translates into a positive differential of $0.9 \%$ of output after two years in the economy with a noisy signal of aggregate prices with respect to the economy with an accurate signal. This result can be traced back to the original idea that larger information frictions delay the response of prices. It is important to note that our result relates the effectiveness of monetary policy to informational uncertainty about the aggregate state, as opposed to fundamental uncertainty. An opposite result is found in Vavra (2014), who examines the effectiveness of monetary policy in the context of higher uncertainty in the stochastic process that governs the underlying economic shocks. ${ }^{2}$

Finally, we use our model to compute the welfare costs of not providing an accurate measure of aggregate prices. We find these to be large. The representative household living in an economy with an accurate measure of aggregate prices requires a decrease in consumption of $4.4 \%$ every period in order to be indifferent to living in an economy with a noisy signal of aggregate prices. Such high welfare costs are associated with higher quantity dispersion, which in turn is welfare reducing for the household since it entails a suboptimal consumption basket. Welfare costs are reduced to half if we consider the exercise in which the increase in the variance of the noise of the signal of aggregate prices is assumed to be transitory and last for five years.

Our paper is related to the strand of the theoretical literature that studies the social value of releasing public information. A bulk of this literature has studied the value of public information in general settings (e.g. Morris and Shin (2002), Angeletos and Pavan (2004) and Angeletos and Pavan (2007)). More recent work by Amador and Weill (2010) shows that the release of public information may reduce the informational content of prices to the point that this negative effect dominates the original positive effect of better public information.

\footnotetext{
${ }^{2}$ Vavra (2014) shows using a menu cost model that the aggregate price level becomes more responsive to nominal shocks during times of high uncertainty, where higher uncertainty is modeled as an increase in the volatility of firm-level productivity. A similar result is found in Baley and Blanco (2013).
} 
Our welfare calculations will not be affected by this effect since the public information refers to the aggregate level of prices which is the only aggregate endogenous source of information.

Our paper also contributes to the literature that studies the relationship between information and price setting. Informational frictions come in several flavors. Part of the literature focuses on the case in which new information arrives in a exogenous staggered fashion, as in Mankiw and Reis (2002) and Klenow and Willis (2007), or endogenously due to costs of acquiring and processing the new information as in Reis (2006) and Alvarez et al. (2011b). The literature about noisy information analyzes price setting models in which agents freely observe imperfect noisy signals (e.g., Woodford (2003), Angeletos and La'O (2009)). Additionally, another strand of the literature focuses in the presence of incomplete information in which the available set of information is insufficient to tell apart the underlying shock of the economy (e.g. Hellwig and Venkateswaran (2009), Hellwig and Venkateswaran (2012) and Baley and Blanco (2013)). Due to the empirical phenomenon at hand, we believe that the last two approaches are more appropriate. In particular, our paper shares the assumption of disperse incomplete information of Hellwig and Venkateswaran (2009) and adds the availability of a noisy signal of the aggregate price level.

The remaining of the paper is organized as follows. Section 2 documents the episode of analysis that we use for identification purposes and briefly describes the dataset and assess its representativeness of the overall economy. Section 3 discusses the empirical strategy, presents the main results and robustness exercises concerning the estimation of the effect of higher uncertainty about inflation on price dispersion. Section 4 presents a general equilibrium model of price setting. A quantitative analysis of the model implications for price dispersion, the effectiveness of monetary policy and welfare is carried out in section 5. Finally, Section 6 concludes.

\section{The Episode of Analysis and Data Description}

\subsection{The Episode of Analysis}

Starting in 2007, the Argentinean government started manipulating official statistics of inflation presumably to prevent figures from reflecting accelerating inflation. As of the writing of this paper, the government just started making changes to potentially provide more credible inflation statistics. The manipulation started in January 2007 with the government's intervention of the the National Statistics and Census Institute (INDEC) and the removal of 
the authorities in charge of computing and publishing the CPI. ${ }^{3}$ Since then official inflation statistics were discredited by local and international media, international institutions and academic circles. $^{4}$

In the absence of an official trustworthy measure of inflation, private and independent institutions gradually started monitoring the evolution of prices and reporting alternative measures of inflation. In addition, some individual provincial governments started reporting their local inflation statistics. As illustrated in Figure (1), during the 2007-12 period, the average official annual inflation rate was $9 \%$, less than half of $21 \%$ average reported by the alternative measures of inflation.

Alternative measures of inflation provided a useful yet imperfect estimate of the true inflation rate. Given their small and unrepresentative samples, significant dispersion was observed among these measures. ${ }^{5}$ The difference between the highest and lowest inflation measures averaged 5 percentage points during the 2007-12 period (see Figure (1)). In addition, there was lack of consensus among economic agents concerning which of these alternative measures provided the best estimate of inflation. ${ }^{6}$ This can be more clearly seen in Figure (2), which shows several moments of the distribution of inflation expectations in Argentina. ${ }^{7}$ At the end of 2006, the average and median expected inflation were both, close among each other and close to the official inflation rate. Since then both measures start to increase, remaining on the upper contour of the different measures of inflation that emerged after 2007 (this is particularly true for the mean expectation of inflation). It is also interesting to notice the insensibility of the mean expected inflation to the apparent decline of inflation between 2009 and 2010. The standard deviation of the expected inflation across individuals follows a

\footnotetext{
${ }^{3}$ See Cavallo (2013) for a description of the event and the particular measures taken by the government.

${ }^{4}$ See, for example, La Nacion, February 10, 2007, The Economist, April 20, 2011, IMF (2008) and Cavallo (2013). In 2012, the IMF censored Argentina for not providing adequate data on inflation.

${ }^{5}$ Some measures are available starting after 2007 and some others were interrupted due to government bans on the publication of alternative measures of inflation.

${ }^{6}$ For example, the IMF does not report any of the alternative measures of inflation, The Economist reports the measure of inflation computed by PriceStats and the Argentinean Congress reports an average of private measures of inflation estimated by local independent economists.

${ }^{7}$ The data comes from the Survey of Inflation Expectations developed by the Universidad Torcuato Di Tella. This is a monthly survey that includes on average 1,100 participants answering the following question:"Comparing current prices with those in the next year, by which percentage do you expect prices to increase on average in the next twelve months?"
} 
Figure 1. Inflation in Argentina Before and After Statistics Manipulation

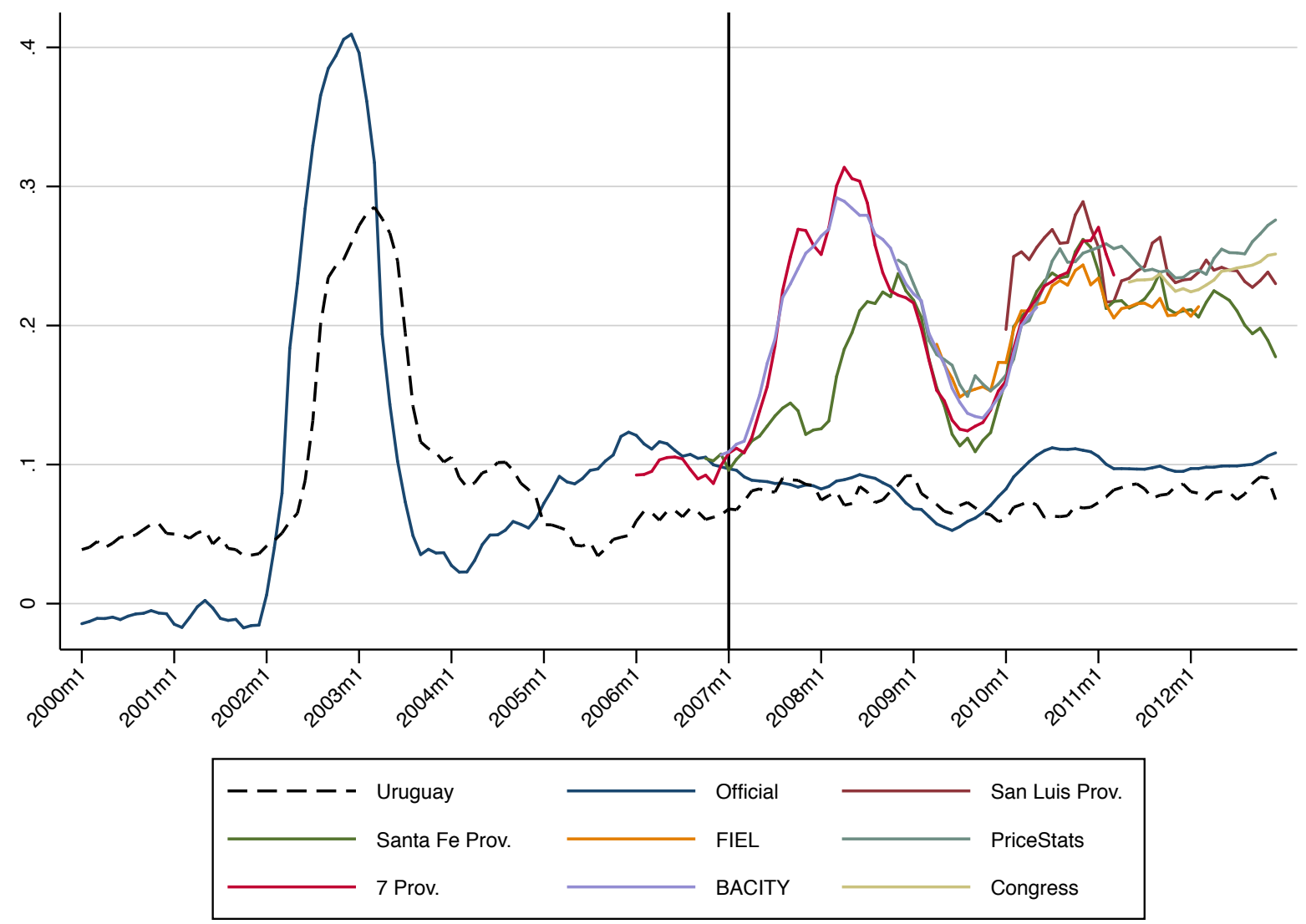

Notes: This figure shows annualized monthly inflation rates for Uruguay and Argentina during the 2000-2012 period. It can be seen how different measures of inflation that emerge after 2007 (denoted by the vertical line) begin to depart from the Argentinean official statistics. Also, some this measures are not that different to the official inflation rate at the end of 2006. This evidence points toward a regime switch in the availability of and access to credible information about the inflation rate.

similar pattern over time, supporting our claim that these alternatives measures of inflation did not provide a perfect substitute to the discredited official inflation rate.

All in all, it can be convincingly argued that during the past decade Argentina has experienced two different regimes concerning the access to public information about the level of inflation. From 2003 to 2006 the government provided a unique and credible official measure of inflation. On the other hand, from 2007 onwards official inflation statistics were discredited and there was overall uncertainty about the true level of inflation in spite of the presence of alternative noisier measures of inflation. Finally, it is important to note that the level of inflation -as measured by the simple average of the alternative measures of inflation- 
was higher during this last period (21\% annual average) than the level of inflation during 2003-2006 (10\% annual average). ${ }^{8}$

Figure 2. Inflation Expectations in Argentina
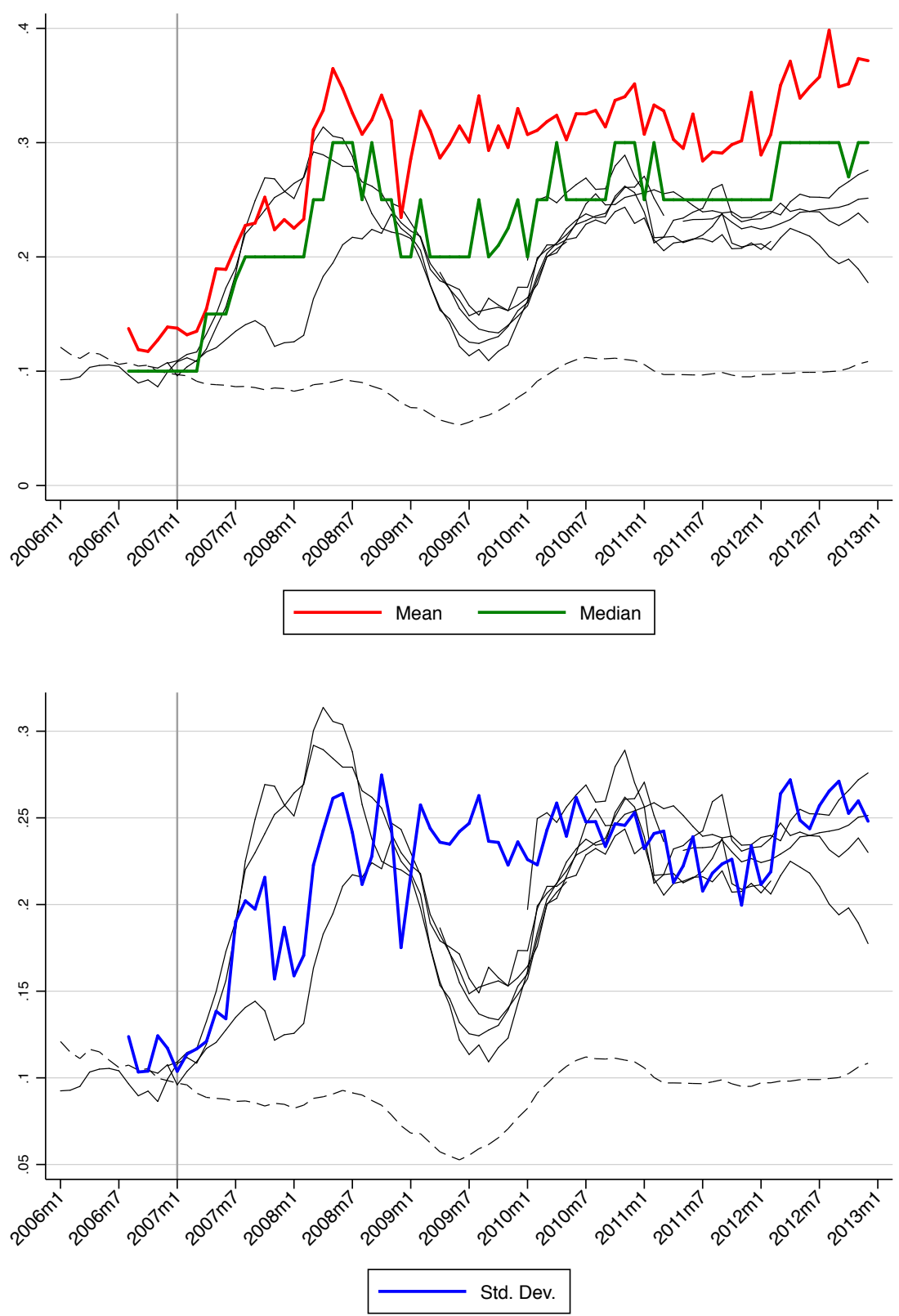

Notes: This figure shows annualized monthly expected inflation rates for Argentina during the 2006-2012 period.

\footnotetext{
${ }^{8}$ However, the highest levels of inflation in the past decade were observed in early 2003 in the aftermath of the economic crisis, when annual inflation peaked above $35 \%$.
} 


\subsection{Data Description}

The data used for the analysis of price dispersion comes from the largest e-trade platform in Latin America that started its activities in 1999 and currently operates in 13 countries with 69.5 million users. We obtained data for all the publications that were made in Argentina and Uruguay during the 2003-12 period. The inclusion of Uruguay serves the purpose of having a control country and will be discussed further in the following section.

In our data an observation consists of a publication made by a seller of a good(s). Some of the observed characteristics of the publications are: a description of the product, the product category, the type of the product (new or used), the posted price including its currency denomination, the quantities available for sale, a seller identifier and the date of publication.

The entire dataset includes more than 140 million publications for both countries during the 2003-2012 period. $82 \%$ of the total publications correspond to Argentina while the remaining correspond to Uruguay (this should not be surprising given the fact that the Argentinean economy is ten times as large as the Uruguayan economy). Most of the publications are concentrated in the last years of our sample as the number of publications grew at a rate of $8.8 \%$ annually on average given the rapid expansion of the site (see Figure (A.1)). We focus our analysis on the publications of new products, that represent $44 \%$ of the total number of publications, for two reasons: i. to exclude the source of heterogeneity in used products that comes from the products' previous usage and ii. to isolate one-time-sellers of used products that are less likely to consider the evolution of inflation when setting prices. We also restrict our sample by dropping publications made in 2003 since the sample size is particularly small for Uruguay, which introduces noise in our results (however, most of our results still hold in the full sample).

The data shows quite heterogeneity in the type of sellers that make use of this online platform. While the median number of units of new products available for sale by publication is 1 , the average quantity offered per publication is 10.8 (see Figure (A.2) for a histogram of the quantities). Similarly, the mean number of publications made by a seller of new products is 3, despite the fact that more than half of the sellers only post one publication (see Figure $(\mathrm{A} .3))$.

An important variable in the empirical analysis will be the category of the product. The platform offers the possibility to the seller to categorize the good being sold according to a pre-specified set of choices. Each product is placed somewhere in a category tree that 
has five levels that go from a more broad to a more specific classification. ${ }^{9}$ The first level of categories indicate broad product types such as computers, books and health/beauty. On the other extreme, the fifth level indicates very detailed products such as a Sony Vaio notebook with Intel Core i7 processor, race bikes for adults or Ray-Ban sunglasses for men (for complete examples of the specification of each category level see Table (1)). As one increases the level of category specification, the number of publications that are categorized under that level decreases. In particular, $92 \%$ of the total number of publications of new products are categorized in level 3 or higher (see Table (1)). It is important to note that technology and electronic-related products constitute an important fraction of the basket of products posted in the sample, even though this fraction has decreased over time (see Figure (A.4) for a snapshot of the basket of products at two different points in time).

The average posted price of a product in a publication in the sample is US\$94. Most of the prices are posted in domestic currency ( $93 \%$ of total publications) and the remaining are posted in US dollars. To make prices comparable across countries we convert all prices to domestic currency using the spot nominal exchange rate at the day of the publication. The posted prices have great variability in a given category and period of time. To remove outliers we drop all prices that are above US $\$ 10,000$ or above the 99th percentile in each category in a given year for a given country. ${ }^{10}$

Despite the large dimensions of the data set, one concern that arises is whether or not the pricing decisions made by users of this online platform are representative of the aggregate economy. As already shown in Figure (A.4), the basket of products offered in the platform differs substantially from the representative basket of products and services in the CPI (just as an example, the platform does not offer food nor services that represent a large share in any basket of the CPI). To address this issue we compute the implicit inflation rate from our database with the evolution of measured aggregate inflation in Argentina. As shown in Figure (3), the implicit inflation closely follows the evolution of the aggregate inflation

\footnotetext{
${ }^{9}$ The category tree also contains two additional levels for a very narrow set of products. Since only $7 \%$ of the total number of publications contain categories specifications that go up to levels 6 or 7 , we decided not to use those narrower classifications.

${ }^{10}$ Similarly, to remove outliers in the posted quantities we also winsorize the posted quantities at 100 units.
} 
Table 1. New Product Publications According to Maximum Category Level

\begin{tabular}{|c|c|c|c|}
\hline Category Level & Observations & $\%$ of Total Obs. & Examples \\
\hline 1 & $63,121,213$ & $100 \%$ & $\begin{array}{l}\text { 1. Computers } \\
\text { 2. Sports \& Fitness } \\
\text { 3. Clothes \& Accessories }\end{array}$ \\
\hline 2 & $63,121,055$ & $100 \%$ & $\begin{array}{l}\text { 1. Notebooks \& Accessories } \\
\text { 2. Biking } \\
\text { 3. Glasses }\end{array}$ \\
\hline 3 & $58,318,807$ & $92 \%$ & $\begin{array}{l}\text { 1. Notebooks } \\
\text { 2. Bicycles } \\
\text { 3. For men }\end{array}$ \\
\hline 4 & $40,349,384$ & $64 \%$ & $\begin{array}{l}\text { 1. Sony Vaio } \\
\text { 2. Adults }\end{array}$ \\
\hline 5 & $17,844,041$ & $28 \%$ & $\begin{array}{l}\text { 3. Sunglasses } \\
\text { 1. Intel Core i7 } \\
\text { 2. Race Bikes } \\
\text { 3. Rav-Ban }\end{array}$ \\
\hline
\end{tabular}

Notes: This table shows the composition of publications of new products according to the maximum level of categorization available. The first (second) column shows the number (percentage) of total publications of new goods that have information on each level of categorization. For example, $92 \%$ of the sample has information about the level 3 of categorization (i.e., only $8 \%$ of the sample has missing information about level 3). The last column gives an example of the type of categorization available for a given product.

(both in co-movement and average levels), arguing in favor of the representativeness of the database. ${ }^{11}$

\section{EMPirical ANALYsis}

\subsection{Identification Strategy and Estimation}

We are interested in estimating the causal effect of higher uncertainty about the rate of inflation on observed price dispersion. To pursue this we will exploit the regime switch in

\footnotetext{
${ }^{11}$ The comparison is not favorable for the first quarters since the number of observations is much lower at the beginning of the sample and the composition of goods was more concentrated on fewer categories.
} 
Figure 3. Observed and Implicit Annual Inflation in Argentina

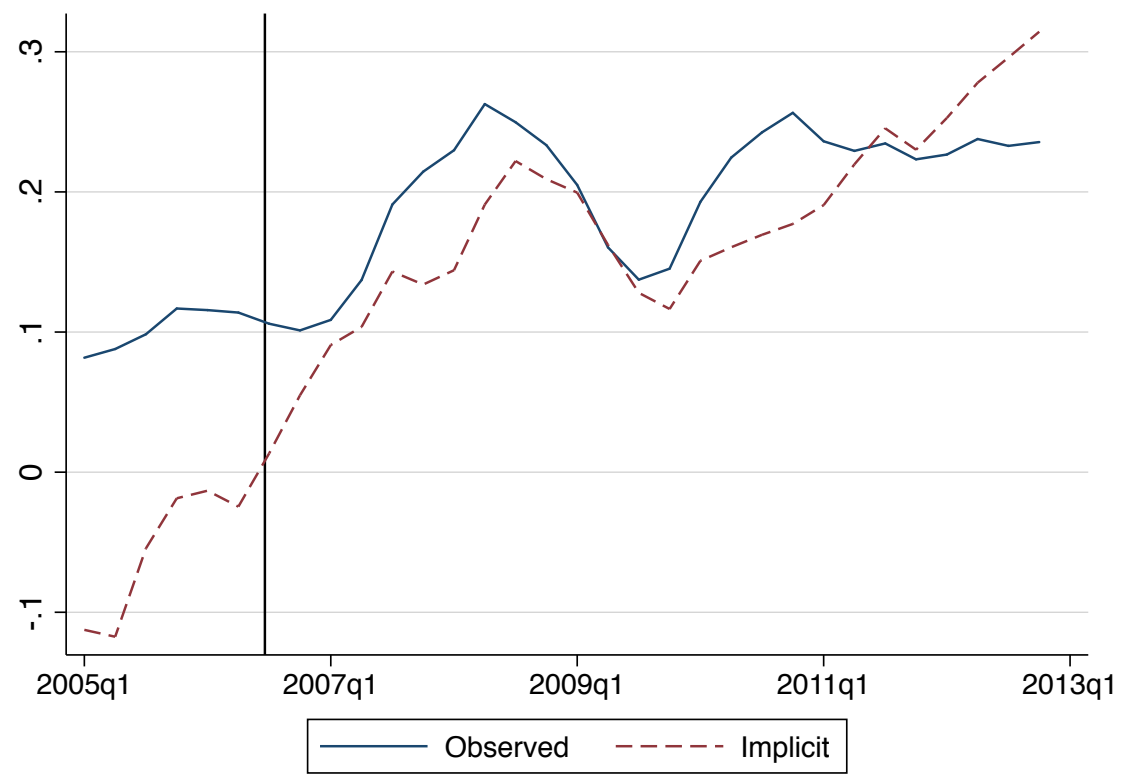

Notes: Observed inflation in Argentina measured by official inflation statistics until 2006 and as the simple average of the alternative measures of inflation for 2007-12. Implicit inflation is computed as the average inflation rates across categories of level 3 .

the access to information about the level of inflation in Argentina due to the exogenous manipulation of official statistics of inflation. In order to isolate our effect of interest from any systemic macroeconomic shock and changes to the online platform, we include Uruguay as a control country and pursue a difference-in-difference analysis. ${ }^{12}$ The choice of Uruguay as the control country is based on two reasons. First, it is a country with similar exposure to external macroeconomic shocks and similar socioeconomic characteristics to Argentina: income per capita in Uruguay is $\$ 16,037$ compared to $\$ 12,034$ in Argentina and the correlation of their annual growth rates (measured on a quarterly basis) is $47 \% .{ }^{13}$ Second, throughout the period of analysis the Uruguayan government has always credibly reported official statistics on inflation.

Having established the two regimes and the control country we can discuss the estimation procedure. In order to obtain a measure of price dispersion we compute the coefficient of variation of prices of all publications in a category for each country and for each quarter in

\footnotetext{
${ }^{12}$ See Card and Krueger (1994) for a pioneer application of the difference-in-difference approach.

${ }^{13}$ Per capita GDP figures correspond to 2012 and the correlation in annual growth rates was calculated for the period 2003-2012. Data was taken from WEO.
} 
the sample period. ${ }^{14}$ Following this procedure gives us a panel of (at most) forty observations for each category in each country. ${ }^{15}$ Our baseline estimations will be computed using the category level 3. This category level provides a sufficiently detailed level of product specification (bicycles, fridges, mattresses, watches and wines are examples of product specifications included in this level) while keeping $92 \%$ of all the observed publications of new products. Robustness estimations will be computed using the alternative category levels.

We will include observed inflation as one of the control variables in our baseline estimations. The main reason for this is that previous literature has found either a positive (Alvarez et al. (2011a), Van Hoomissen (1988)) or negative (Reinsdorf (1994)) relation between inflation and price dispersion. In our particular case, aggregate inflation increased in Argentina at the time of the manipulation of statistics. By including observed inflation as a regressor we are estimating an underlying relationship between inflation and price dispersion that will help us identify how much of the variation in price dispersion in both regimes is due to an increase in inflation and how much is due to the lose in access to information about the level of inflation. We also include quarterly time fixed effects to control for any aggregate shock in the evolution of price dispersion that affected both countries alike and category-country fixed effects to control for time-invariant influences. ${ }^{16}$ Our baseline difference-in-difference estimations are thus based on the following empirical model:

$$
\text { PriceDispersion }_{c i t}=\delta \mathbb{I}_{\{t \geq 2007, c=\text { Arg. }\}}+\beta_{1 c} \pi_{c t}+\beta_{2 c} \pi_{c t}^{2}+\alpha_{t}+\alpha_{c i}+\varepsilon_{c i t}
$$

where:

PriceDispersion $_{\text {cit }}$ is the coefficient of variation of prices of all publications in a given quarter $t$, category $i$ and country $c$.

$\mathbb{I}_{\{t \geq 2007\}}$ is an indicator variable that equals 1 for quarters in years 2007 or after (post inflation statistics manipulation).

\footnotetext{
${ }^{14}$ The coefficient of variation is defined as the ratio of the sample standard deviation to the sample mean. This measure has the advantage of being dimensionless (in particular it will not depend on the currency in which prices are expressed). Alternative measures of price dispersion such as the standard deviation of the log of prices and inter-quartile ranges will also be considered.

${ }^{15}$ The panel will not be balanced for all category levels as some levels where introduced after 2003 and we do not always observe publications in all category levels for all quarters. Additionally, our quarterly aggregation is arbitrary. Similar results are obtained when we aggregate the data at the monthly level.

${ }^{16}$ Given the large expansion of the online platform, time fixed effects will also control for a common time trend in the behavior of the online platform for both countries.
} 
$\mathbb{I}_{\{t \geq 2007, c=A r g .\}}$ is an indicator variable that equals 1 for quarters in years 2007 or after (post inflation statistics manipulation) interacted with an indicator variable that equals 1 for publications made in Argentina.

$\pi_{c t}$ is the annual inflation rate observed in quarter $\mathrm{t}$ for country c (i.e. the variation between quarter $t$ and quarter $t-4 \mathrm{CPI}$ ). For the case of Argentina we use the official inflation measure until 2006 and the simple average of the available alternative measures of annual inflation from 2007 onwards.

$\alpha_{t}$ are quarter fixed effects.

$\alpha_{c i}$ are category-country fixed effects.

$\varepsilon_{c i t}$ is an error term. ${ }^{17}$

The identifying assumption that we make in order to estimate a casual effect is that, conditional on the inflation rate, the policy decision of manipulating inflation statistics is exogenous to the evolution of price dispersion. It has been argued that authorities started manipulating inflation statistics to prevent figures from reflecting accelerating inflation and at the same time save fiscal resources by paying less interest on inflation-linked sovereign bonds. ${ }^{18}$ By controlling for the evolution of aggregate inflation, we can identify the casual effect of the policy on price dispersion. ${ }^{19}$

\subsection{Results}

A visual inspection of the behavior of price dispersion in both countries across time is already informative of the effects of the policy. Figure (4) plots the evolution of the mean price dispersion across categories for a given quarter and a given country. The difference

\footnotetext{
${ }^{17}$ Following the recommendations of Bertrand et al. (2004), we cluster the standard errors at the categorycountry level unless noted otherwise.

${ }^{18}$ See, for example, The Economist, February 25, 2012 which discusses the intervention of inflation statistics in Argentina: "What seems to have started as a desire to avoid bad headlines in a country with a history of hyperinflation has led to the debasement of INDEC, once one of Latin America's best statistical offices. (...) Misreported prices have cheated holders of inflation-linked bonds out of billions of dollars."

${ }^{19}$ The fact that inflation in Argentina during the first quarters of 2003 was higher than the levels post 2007 helps us identify the casual effect. An additional identifying assumption is that the implicit economic relation is between price dispersion and the observed level of inflation, as opposed to theories that may link price dispersion and inflation expectations (as it could be argued that inflation expectations could have been highly collinear with our identified regimes).
} 
between price dispersion in Argentina and Uruguay increases after the manipulation of inflation statistics took place in Argentina suggesting that the policy might have caused an increase in price dispersion.

Figure 4. Median Coefficient of Variation Across Categories by Country

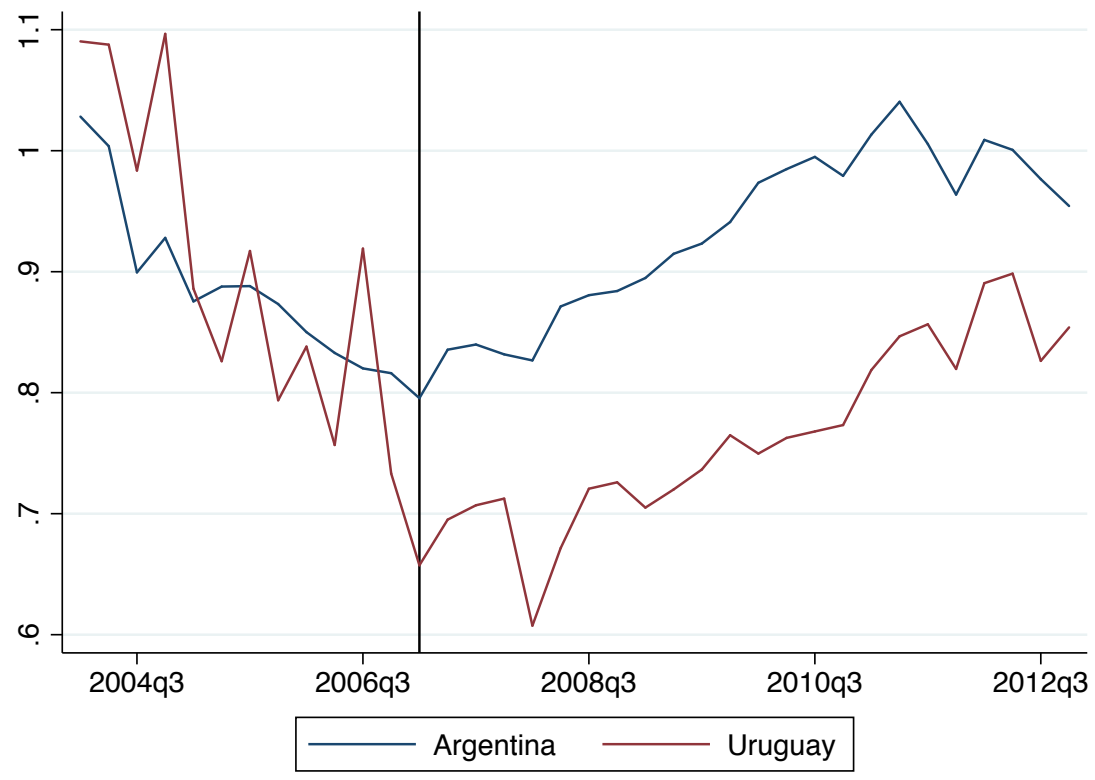

Notes: This figure shows the mean coefficient of variation across categories of level 4 by quarter and country. The sample used in this figure is restricted to categories with data for at least 20 (out of a maximum of 40) quarters. The vertical line represents the first quarter of 2007, when the treatment began in Argentina.

Table (2) reports our basic regression estimates that formally quantify the visual effect just described. Column (4) shows the results of the benchmark estimation that includes both time fixed effects and category-country fixed effects. The coefficient associated to the interaction between the indicator of Argentina and the indicator of post 2007 is positive and significant. Regressions (1)-(3) estimate similar specifications dropping time and category-country fixed effects one at a time. The difference-in-difference effect remains positive and significant in all specifications with the exception of the estimation without time and country-category fixed effects in which the coefficient looses significance. Note that when category-country fixed effects are included the identification of the effect comes only from those categories for which we have observations in the pre and post-treatment period. In the specifications where category-country fixed effects are not included the identification comes from all categories even if we do not have observations for both periods. 
In order to capture the fact that effective price dispersion is related to the quantities of the product that are offered at a particular price, we compute a weighted coefficient of variation where the weights are given by the quantity available for sale in each publication. When we use the weighted version of the coefficient of variation (regressions (5)-(8)) the coefficient of interest is positive and significant in all specifications. The effects are also larger than in the specifications with the unweighted measure of the coefficient of variation.

The effect of higher uncertainty about inflation caused by the manipulation of inflation statistics on observed price dispersion is large in economic terms. If we consider the results from the baseline specification in column (4) the difference-in-difference coefficient of 0.212 indicates that the price dispersion of products published in Argentina is $18 \%$ higher than average after the manipulation of inflation statistics. In other words, the higher uncertainty about the levels of inflation that emerged due to the manipulation of official statistics yielded an increase in the price dispersion of $18 \%$. For the rest of the paper we will take the specification in column (4) (which uses the unweighted coefficient of variation as a measure of price dispersion and includes time and category-country fixed effects) as our benchmark specification.

\subsection{Robustness}

In this subsection we present further analysis that helps us assess the validity of our results. We present robustness checks that dwell with three particular aspects: the choice of the dependent variable, the functional form of the estimation equation and the identification strategy.

In order to assess the robustness of the effect to the choice of the dependent variable we compute our baseline estimation for alternative measures of price dispersion: the standard deviation of log prices, the 75-25 interquartile range and the 90th-10th percentile range. ${ }^{20}$ Results are shown in Table (3). The difference-in-difference coefficient remains positive and significant in all of the specifications with alternative dependent variables. For the specification with the standard deviation of log prices the effect is of the order of $44 \%$ relative to the average of the dependent variable for Argentina and for the specifications of 75-25 and 90-10 percentile ranges the effect is 14\% in both cases, which is closer to the $18 \%$ effect obtained with the coefficient of variations as the dependent variable.

\footnotetext{
${ }^{20}$ The 75-25 interquartile range is defined as the difference between the price in the 75 th percentile and the price in the 25 th percentile normalized by the average price of goods in a given category to make units comparable. An analogous definition applies for the 90-10 90th-10th percentile range.
} 


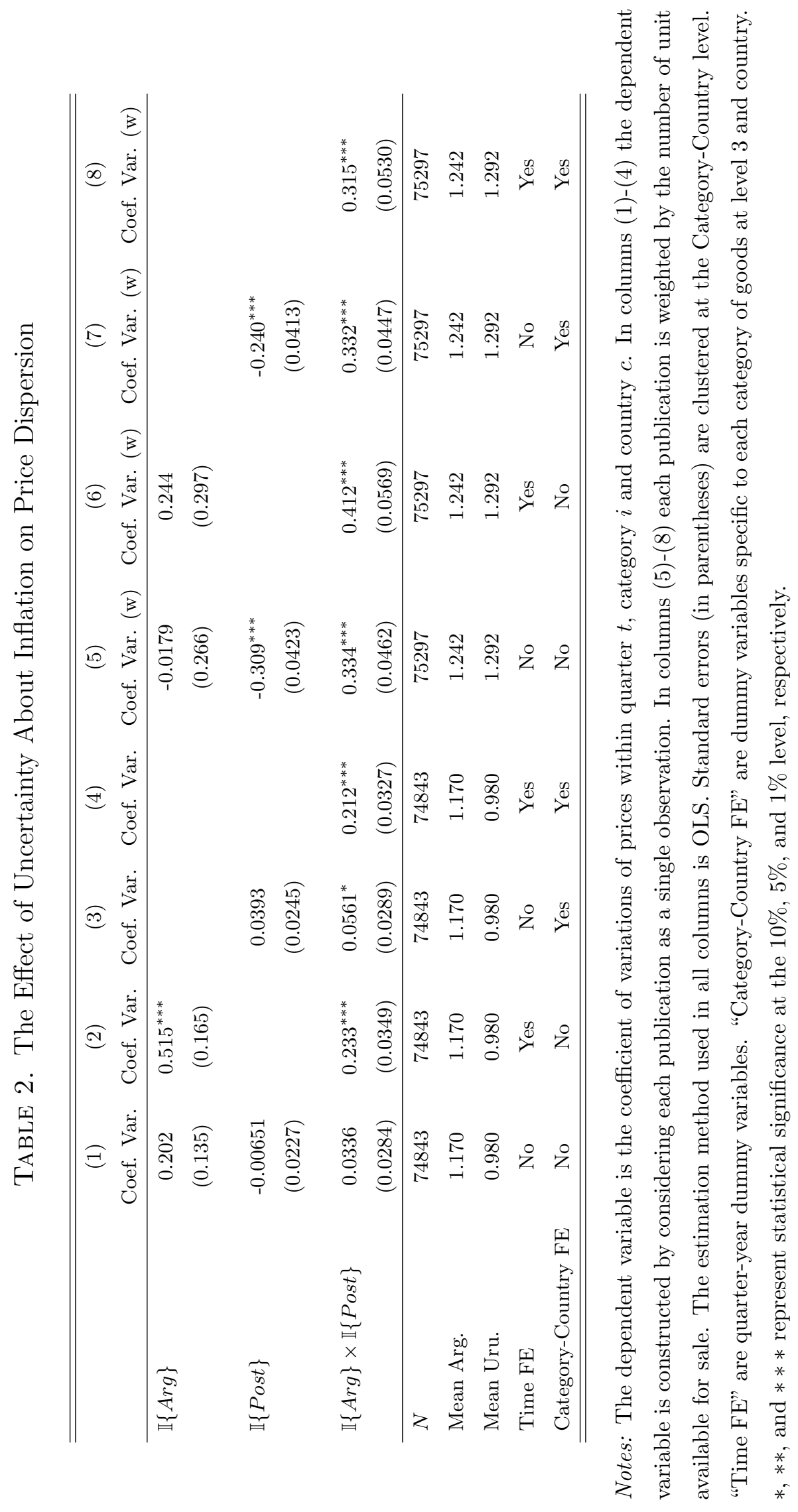


TABLe 3. Robustness Analysis: Different Dependent Variables

\begin{tabular}{lcccc}
\hline \hline & $(1)$ & $(2)$ & $(3)$ & $(4)$ \\
& Baseline & SD $\log (\mathrm{P})$ & $\mathrm{IQ75-25}$ & $\mathrm{IQ90-10}$ \\
\hline $\mathbb{I}\{$ Arg $\} \times \mathbb{I}\{$ Post $\}$ & $0.212^{* * *}$ & $0.474^{* * *}$ & $0.118^{* * *}$ & $0.264^{* * *}$ \\
& $(0.0327)$ & $(0.0324)$ & $(0.0283)$ & $(0.0487)$ \\
\hline$N$ & 74843 & 74843 & 75829 & 75829 \\
Mean Arg. & 1.170 & 1.065 & 0.805 & 1.857 \\
Mean Uru. & 0.980 & 1.460 & 0.796 & 1.667 \\
Time FE & Yes & Yes & Yes & Yes \\
Category-Country FE & Yes & Yes & Yes & Yes \\
\hline \hline
\end{tabular}

Notes: The dependent variable in the Baseline column (1) is the unweighted coefficient of variation. The dependent variables in columns (2)-(4) are the standard deviation of log prices, the 75th-25th percentile range standardized by the mean price and the 90th-10th percentile range standardized by the mean price, respectively. The estimation method used in all columns is OLS. All specifications include inflation and inflation squared as controls (omitted), in addition to Time fixed effects and Category-Country fixed effects. Standard errors (in parentheses) are clustered at the Category-Country level. $*, * *$, and $* * *$ represent statistical significance at the $10 \%, 5 \%$, and $1 \%$ level, respectively.

The inclusion of inflation and the square of inflation as independent variables to allow for a more flexible functional form in the estimation equation was arbitrary. To assess the robustness of our results to these choices we estimated different specifications that vary in the functional form in which inflation enters the regression equation. First, we re-estimate our baseline specification with inflation entering linearly and as a third degree polynomial. Results are shown in columns (2) and (3) of Table (4), and it can be seen that the differencein-difference coefficient remains positive and significant. We also estimate a version of the estimation equation in which the relationship between inflation and price dispersion is restricted across countries. The difference-in-difference coefficient still remains positive and significant for this specification as well, as indicated in column (4).

Similarly, the modeling of the effect of the policy as a step function that is permanent also involves a judgment call. To address this issue we estimate our baseline specification altering our treatment variable. In particular, we estimate a linear effect over time and a log effect over time (as opposed to our benchmark estimation of a step permanent effect). These results of the linear and log specifications are shown in columns (5) and (6) respectively. For the linear case, the coefficient is still positive and significant (only at the $10 \%$ level). For the log case, the coefficient of interest is positive and significant at the $1 \%$ level. Results 
suggest that the effect of higher uncertainty about the levels of inflation on price dispersion was either a step increase or a gradual effect that accumulates at a decreasing rate over time.

TABLE 4. Robustness Analysis: Functional Form Specification

\begin{tabular}{|c|c|c|c|c|c|c|}
\hline & $(1)$ & (2) & (3) & $(4)$ & $(5)$ & $(6)$ \\
\hline & Baseline & Coef. Var. & Coef. Var. & Coef. Var. & Coef. Var. & Coef. Var. \\
\hline \multirow[t]{2}{*}{$\mathbb{I}\{$ Arg $\} \times \mathbb{I}\{$ Post $\}$} & $0.212^{* * *}$ & $0.136^{* * *}$ & $0.194^{* * *}$ & $0.125^{* * *}$ & & \\
\hline & $(0.0327)$ & $(0.0289)$ & $(0.0317)$ & $(0.0275)$ & & \\
\hline \multirow[t]{2}{*}{$\mathbb{I}\{A r g\} \times q_{\text {post }, t}$} & & & & & $0.00266^{*}$ & \\
\hline & & & & & $(0.00140)$ & \\
\hline \multirow[t]{2}{*}{$\mathbb{I}\{\operatorname{Arg}\} \times \log \left(q_{\text {post }, t}\right)$} & & & & & & $0.0687^{* * *}$ \\
\hline & & & & & & $(0.0130)$ \\
\hline$N$ & 74843 & 74843 & 74843 & 74843 & 74843 & 74843 \\
\hline Mean Arg. & 1.170 & 1.170 & 1.170 & 1.170 & 1.170 & 1.170 \\
\hline Mean Uru. & 0.980 & 0.980 & 0.980 & 0.980 & 0.980 & 0.980 \\
\hline Time FE & Yes & Yes & Yes & Yes & Yes & Yes \\
\hline Category-Country FE & Yes & Yes & Yes & Yes & Yes & Yes \\
\hline Specification & & 1st Deg. Inf. & 3rd Deg. Inf. & Restricted Infl. & Linear Effect & Log Effect \\
\hline
\end{tabular}

Notes: The dependent variable in all columns is the coefficient of variations of prices within quarter $t$, category $i$ and country $c$. In columns (2) and (3) we include a first and third degree polynomial of inflation as controls. In column (4) we include a second degree polynomial of inflation, restricting the coefficients to be the same across countries. In column (5) we replace the indicator of the 2007-2012 period by a linear function of quarters since the first quarter of 2007 (linear effect over time). In column (6) we replace the indicator of the 2007-2012 period by the logarithm of the number of quarters since the first quarter of 2007 (log effect over time). The estimation method used in all columns is OLS. Standard errors (in parentheses) are clustered at the Category-Country level. "Time FE" are quarter-year dummy variables. "CategoryCountry FE" are dummy variables specific to each category of goods at level 3 and $\operatorname{country}$. $*, * *$, and $* * *$ represent statistical significance at the $10 \%, 5 \%$, and $1 \%$ level, respectively.

A potential objection to our analysis is that the coefficient of interest could be capturing the effect of other major economic policies potentially related to price dispersion that took place in Argentina or Uruguay around the same time period of the manipulation of inflation statistics. In the case of Uruguay no major economic policies that could potentially affect price dispersion were put in place during our sample period. In the case of Argentina the government implemented policies aimed at reducing trade and capital flows. In particular, starting in 2008/09 the Argentinean government introduced administrative delays on imports 
licensing. ${ }^{21}$ Additionally, in October 2011 the government imposed foreign exchange controls to prevent capital flights. ${ }^{22}$ To ensure that we are indeed capturing the effect of our policy of interest and not the effect of these other policies we exploit the time dimension of the introduction of these different policies and estimate our baseline specification for shorter sample periods that end before 2012. Specifically, we estimate our main regression for the subsamples 2004-2008 and 2004-2010. Results are shown in columns (2) and (3) of Table (5), respectively. The difference-in-difference coefficient is positive and significant at the $5 \%$ level for the subsample 2004-2008 and positive and significant at the 1\% level for the 2004-2010 subsample.

It could also be argued that statistical significance should be somewhat expected given the large dimension of our dataset. In order to strengthen the validity of our identified effect we designed a placebo test that consisted of estimating our baseline regression for the 2004-2006 sub-period, considering the year 2006 as the treatment period for Argentina. Results are shown in column (4) of Table (5). The difference-in-difference coefficient in this case is small and not significantly different from zero, an expected result given that the policy was not in place during 2006.

In order to provide further evidence that the timing of our identified effect coincides exactly with the timing of the policy in Argentina we estimate our baseline specification and add semester-specific dummy variables interacted with the indicator of Argentina for the entire sample period. The flexibility of this specification helps us to identify when the effect starts being significantly different from zero. As depicted in Figure (5), the time-varying coefficients are not statistically different from zero prior to the treatment, and start being positive and statistically significant immediately after the treatment begins, remaining positive and significant thereon. ${ }^{23}$ The figure provides reassuring evidence that we are capturing our effect of interest and not the effect of other subsequent policy. Additionally, the figure also reveals that the effect on price dispersion was cumulative over time increasing at a decaying rate.

Another potential concern about our results, is that they could be driven by a bad choice of the control country. For this reason we performed a time series analysis in which we only use the time series variation from Argentina and discard Uruguay as the control group. The

\footnotetext{
${ }^{21}$ The adoption of these measures gave rise to concern of major countries in several WTO meetings of 2011-12. See http://www.wto.org/english/news_e/news12_e/impl_27apr12_e.htm

${ }^{22}$ See, for example, The Economist, November 1, 2011, that analyzes Argentina's currency controls.

${ }^{23}$ The discontinuity of the figure is due to the fact that we choose to omit the second semester of 2006 (the semester previous to the beginning of the treatment in Argentina) and treat it as a benchmark.
} 
TABle 5. Robustness Analysis: Time Horizon and Time Series Analysis

\begin{tabular}{lcccc}
\hline \hline & $(1)$ & $(2)$ & $(3)$ & $(4)$ \\
& Baseline & $\begin{array}{c}\text { Coef. Var. } \\
\text { Coef. Var. }\end{array}$ & Coef. Var. \\
\hline $\mathbb{I}\{$ Arg $\} \times \mathbb{I}\{$ Post $\}$ & $0.212^{* * *}$ & $0.0814^{* *}$ & $0.183^{* * *}$ & \\
& $(0.0327)$ & $(0.0359)$ & $(0.0328)$ & \\
$\mathbb{I}\{$ Arg $\} \times \mathbb{I}\{$ Placebo $\}$ & & & & 0.0583 \\
& & & & $(0.0496)$ \\
\hline$N$ & 74843 & 29202 & 50637 & 14016 \\
Mean Arg. & 1.170 & 1.170 & 1.170 & 1.170 \\
Mean Uru. & 0.980 & 0.980 & 0.980 & 0.980 \\
Time FE & Yes & Yes & Yes & Yes \\
Category-Country FE & Yes & Yes & Yes & Yes \\
Time Horizon & & $2004-2008$ & $2004-2010$ & Placebo \\
\hline \hline
\end{tabular}

Notes: The dependent variable in all columns is the coefficient of variations of prices within quarter $t$, category $i$ and country $c$. The first column runs the OLS regression over the entire sample (2004-2012). Columns (2)(4) run the regression over different subsamples, indicated by the row "Time Horizon". Column (5) reports the results of a Placebo test, in which the sample is restricted to the 2004-2006 period and the year 2006 is considered as the treatment period for Argentina. In the last column we drop from the regression all the observations from Uruguay and the time fixed effects. The estimation method used in all columns is OLS. Standard errors (in parentheses) are clustered at the Category-Country level. "Time FE" are quarter-year dummy variables. "Category-Country FE" are dummy variables specific to each category of goods at level 3 and country. $*, * *$, and $* * *$ represent statistical significance at the $10 \%, 5 \%$, and $1 \%$ level, respectively.

last column of Table (5) presents the results. Although the coefficient is lower in comparison to the baseline result, we still observe a highly significant positive effect of $11 \%$.

Finally, we assess whether the effect of higher uncertainty about the levels of inflation has differential effects on price dispersion depending on the level of substitutability of the products considered. To assess this we exploit the different levels of product categories available in our sample. Our working assumption is that the elasticity of substation is higher for higher levels of categories, as in these categories products are more similar to each other. We estimate our baseline specification for category levels 1 to 5 . Results are shown in Table (6). The coefficient of interest is positive and significant for category levels 2 to 5 and similar in magnitude. However, the effect measured relative to the sample mean is increasing in the level of category. ${ }^{24}$ We interpret this result in the following way: for a given

\footnotetext{
${ }^{24}$ The sample mean of the coefficient of variation is decreasing in the category level, which is consistent with the fact that products are more similar to each other in higher levels of categories.
} 
FiguRE 5. The Effect of Uncertainty over Time

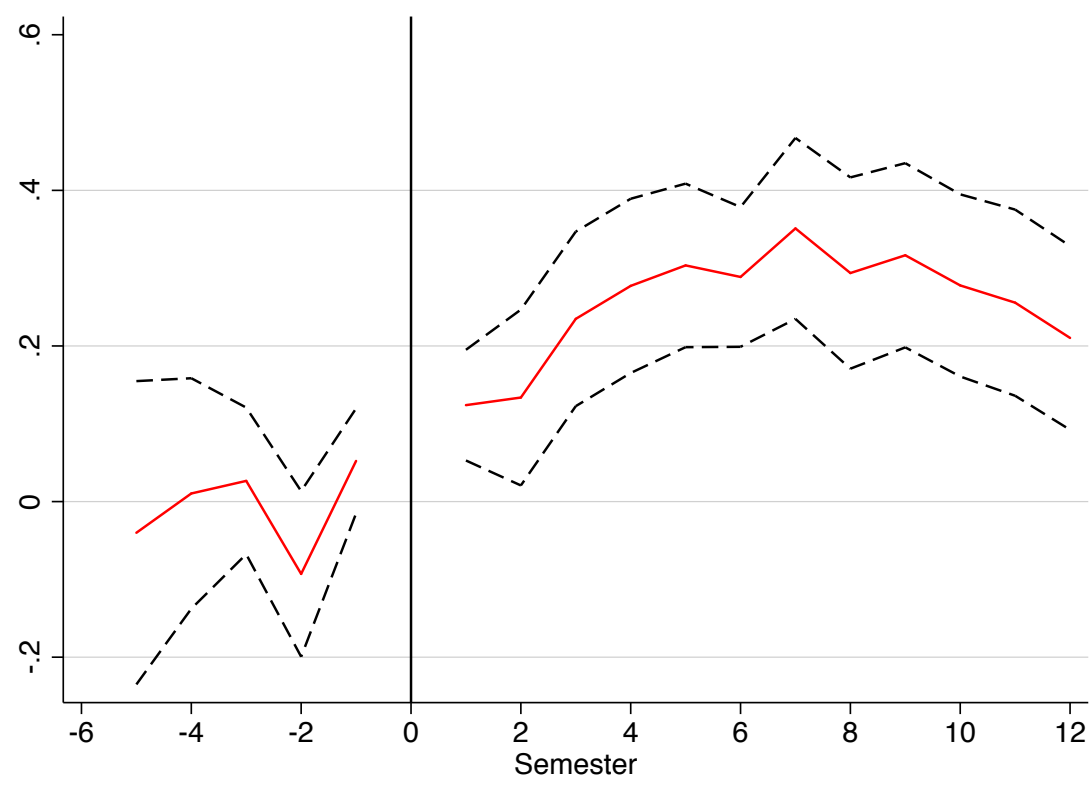

Notes: This figure shows the estimated coefficients for the interaction between semester-specific dummy variables and the indicator of Argentina for the entire period (2004-2012). The omitted semester (depicted as semester "0") is the second semester of 2006, the semester previous to the beginning of the treatment in Argentina. The error bounds are the $95 \%$ confidence intervals $( \pm 1.96 \times S E)$. The estimation method used is OLS. Standard errors are clustered at the Category-Country level. The regression includes inflation and inflation squared as controls (allowing the coefficients to differ across countries), and Time and CategoryCountry fixed effects.

shock to the availability of precise information about inflation, the effect on price dispersion is higher, the higher the elasticity of substitution between products. In order to provide a deeper understanding of this last result we need a theory in place that can shed light on the mechanisms behind these effects. Section 4 will provide such a model and this discussion will be reopened in section 5 . 
TABle 6. Effect on Price Dispersion for Different Category Levels

\begin{tabular}{lccccc}
\hline \hline & $(1)$ & $(2)$ & $(3)$ & $(4)$ & $(5)$ \\
& Coef. Var. & Coef. Var. & Coef. Var. & Coef. Var. & Coef. Var. \\
\hline $\mathbb{I}\{$ Arg $\} \times \mathbb{I}\{$ Post $\}$ & 0.0955 & $0.258^{* * *}$ & $0.212^{* * *}$ & $0.157^{* * *}$ & $0.176^{* *}$ \\
& $(0.198)$ & $(0.0530)$ & $(0.0327)$ & $(0.0433)$ & $(0.0739)$ \\
\hline$N$ & 1512 & 17681 & 74843 & 127760 & 116299 \\
Mean Arg. & 2.323 & 1.516 & 1.170 & 0.888 & 0.695 \\
Mean Uru. & 2.198 & 1.381 & 0.980 & 0.772 & 0.793 \\
Time FE & Yes & Yes & Yes & Yes & Yes \\
Category-Country FE & Yes & Yes & Yes & Yes & Yes \\
Categ. Level & 1 & 2 & 3 & 4 & 5 \\
\hline \hline
\end{tabular}

Notes: The dependent variable in all columns is the coefficient of variations of prices within quarter $t$, category $i$ and country $c$. Columns (1)-(5) run the baseline specification restricting the sample to publications with information at category level 1 to 5, respectively. The estimation method used in all columns is OLS. Standard errors (in parentheses) are clustered at the Category-Country level. "Time FE" are quarter-year dummy variables. "Category-Country FE" are dummy variables specific to each category of goods at level 3 and country. $*, * *$, and $* * *$ represent statistical significance at the $10 \%, 5 \%$, and $1 \%$ level, respectively.

\section{A Model of Price Setting With Incomplete and Noisy Information}

In this section we formulate a price-setting general equilibrium model with monopolistically competitive firms. Our theoretical framework builds on Hellwig and Venkateswaran (2009) model of price setting with incomplete and dispersed information and adds additional sources of aggregate information regarding the level of aggregate prices. Firms make use of a noisy publicly-available signal of the aggregate level of prices, together with idiosyncratic information about their revenues and costs to set their prices. By changing the noise associated to the aggregate signal we can investigate the effect of different degrees of uncertainty about aggregate inflation.

Given their information set, firms cannot perfectly tell apart the realization of all the shocks in the economy. The presence of incomplete information will give rise to money nonneutrality, as noted in earlier works of Phelps (1970) and Lucas (1972). This will allow the model to give insights about the relationship between the degree of uncertainty about the aggregate level of prices and the effectiveness of monetary policy. In order to place focus on the role of the availability of public information in firms' pricing decisions we keep the rest of the model close to the standard Neo-Keynesian benchmark. 


\subsection{Households}

There is a continuum of identical infinitely-lived households whose preferences are defined over a continuum of varieties of goods $C_{i t}$, a continuum of types of labor supply $L_{i t}$ and real money balances $\frac{M_{t}}{P_{t}}$. The expected lifetime utility of households is given by

$$
\mathbb{E}\left(\sum_{t=0}^{\infty} \beta^{t}\left[\frac{C_{t}^{1-\gamma}}{1-\gamma}-\int_{0}^{1} \Phi_{i t} L_{i t} \mathrm{~d} i+\ln \left(\frac{M_{t}}{P_{t}}\right)\right]\right)
$$

where $C_{t}$ is the Dixit-Stiglitz composite of individual goods with elasticity of substitution $\theta$

$$
C_{t}=\left[\int_{0}^{1} \Psi_{i t}^{1 / \theta} C_{i t}^{(\theta-1) / \theta} \mathrm{d} i\right]^{\theta /(\theta-1)}
$$

Consumption preferences of good $i$ are affected by the preference shock $\Psi_{i t}$ and labor preferences are affected by a shock to the disutility of labor of type $i, \Phi_{i t}$, both of which are known to the household at time $t$. The log of these shocks is assumed to follow independent $\operatorname{AR}(1)$ processes

$$
\begin{array}{rlrl}
\ln \Psi_{i t} & =\rho_{\Psi} \ln \Psi_{i t-1}+\sigma_{\Psi} \varepsilon_{i t}^{\Psi} & & \varepsilon_{i t}^{\Psi} \sim N(0,1) \\
\ln \Phi_{i t}=\rho_{\Phi} \ln \Phi_{i t-1}+\sigma_{\Phi} \varepsilon_{i t}^{\Phi} & \varepsilon_{i t}^{\Phi} \sim N(0,1)
\end{array}
$$

Households have access to riskless one-period bonds $B_{t}$ in addition to money for savings purposes. The problem of the household involves choosing a vector $\left\{C_{i t}, L_{i t}, M_{t}, B_{t}\right\}_{t=0}^{\infty}$ to maximize (2) subject to the budget constraint

$$
M_{t}+\frac{B_{t}}{1+i_{t}}+\int_{0}^{1} P_{i t} C_{i t} \mathrm{~d} i=M_{t-1}+B_{t-1}+\int_{0}^{1} W_{i t} L_{i t} \mathrm{~d} i+\Pi_{t}+T_{t}
$$

where $\Pi_{t}$ represents the aggregate profits from the ownership of firms, $T_{t}$ are lump sum transfers of money from the central bank, $i_{t}$ denotes the risk-free nominal interest, $W_{i t}$ is the wage and $P_{i t}$ is the price of goods of type $i$. We characterize the solution to the household's problem by the set of first order conditions

$$
\begin{array}{ll}
\left(C_{i t}\right): & \beta^{t} C_{t}^{1 / \theta-\gamma} \Psi_{i t}^{1 / \theta} C_{i t}^{-1 / \theta}=\lambda_{t} P_{i t} \\
\left(L_{i t}\right): & \beta^{t} \Phi_{i t}=\lambda_{t} W_{t} \\
\left(B_{i t}\right): & -\frac{\lambda_{t}}{1+i_{t}}+\mathbb{E}_{t}\left[\lambda_{t+1}\right]=0 \\
\left(M_{t}\right): & \frac{\beta^{t}}{M_{t}}=\lambda_{t}-\mathbb{E}\left[\lambda_{t+1}\right]
\end{array}
$$


where $\lambda_{t}$ is the Lagrange multiplier corresponding to the budget constraint of period $t$ and state of the economy $s$ (not explicitly written for expositional purposes).

We assume that money supply follows the following stochastic process

$$
\log \left(M_{t+1}\right)=\log \left(M_{t}\right)+\mu+\sigma_{m} \varepsilon_{t+1}^{m} \quad \varepsilon_{t+1}^{m} \sim N(0,1)
$$

Combining (6) and (7) and using the fact that the log of money follows a random walk gives a constant nominal interest rate

$$
(1+\bar{i})=\frac{1}{\beta}\left(E_{t}\left(\frac{M_{t}}{M_{t+1}}\right)\right)^{-1}=\frac{1}{\beta} \exp \left(\mu-\frac{\sigma_{\nu}^{2}}{2}\right)
$$

Given the linearity of preferences with respect to labor, equations (5), (6) and (7) imply

$$
W_{i t}=\kappa \Phi_{i t} M_{t}
$$

where $\kappa \equiv \frac{\bar{i}}{1+i}$. Thus, nominal wages paid for variety $i$ are proportional to the idiosyncratic marginal disutility of labor and aggregate money supply. In absence of the idiosyncratic disturbances $\Phi_{i t}$, firms would be able to perfectly infer the aggregate state, i.e. money supply, from the wages paid to its employees. If we want information about past values of the CPI to provide useful information to the firm, we must prevent this learning via paid wages, which we do by including the idiosyncratic shocks to the disutility of each variety of labor.

Equations (4), (6) and (7) lead to a demand function for each variety given by

$$
C_{i t}=\Psi_{i t} C_{t}^{1-\gamma \theta}\left(\frac{\kappa M_{t}}{P_{i t}}\right)^{\theta}
$$

Replacing this expression in the Dixit-Stiglitz aggregator we can find an expression for aggregate consumption

$$
C_{t}=\left(\frac{\kappa M_{t}}{P_{t}}\right)^{1 / \gamma}
$$

where $P_{t}=\left(\int_{0}^{1} \Psi_{i t} P_{i t}^{1-\theta} \mathrm{d} i\right)^{1 /(1-\theta)}$ is the ideal price index. Thus, the demand of each variety is given by

$$
C_{i t}=\Psi_{i t}\left(\frac{P_{i t}}{P_{t}}\right)^{-\theta}\left(\frac{\kappa M_{t}}{P_{t}}\right)^{1 / \gamma}
$$




\subsection{Firm's Problem}

There is a continuum of firms, each of which sells one variety of the consumption good indexed by $i$. Firms are monopolistically competitive and face the demand derived from the household's problem given by equation (9). The production function of the firm is given by:

$$
Y_{i t}=L_{i t}^{\alpha} \quad \alpha<1
$$

The firm's problem is to maximize expected profits (discounted by the appropriate pricing kernel $\left.\lambda_{t}\right)$

$$
\max _{P_{i t}} \mathbb{E}_{t}\left[\lambda_{t}\left(P_{i t} C_{i t}-W_{i t} L_{i t}\right) \mid \mathcal{I}_{i t}\right]
$$

where $\mathbb{E}_{t}\left[\cdot \mid \mathcal{I}_{i t}\right]$ denotes the expectation operator at period $t$ conditional on the firm-specific information set $\mathcal{I}_{i t}$ (which will be defined below). By replacing the expressions that define the firm's demand (equation (9)) and the nominal wage (equation (8)) we can re-express the firm's optimization problem as

$$
\max _{P_{i t}} \mathbb{E}_{t}\left[\frac{\Phi_{i t}}{W_{i t}}\left(P_{i t} \Psi_{i t}\left(\frac{P_{i t}}{P_{t}}\right)^{-\theta}\left(\frac{\kappa M_{t}}{P_{t}}\right)^{1 / \gamma}-W_{i t}\left(\Psi_{i t}\left(\frac{P_{i t}}{P_{t}}\right)^{-\theta}\left(\frac{\kappa M_{t}}{P_{t}}\right)^{1 / \gamma}\right)^{1 / \alpha}\right) \mid \mathcal{I}_{i t}\right]
$$

The optimal price set by the firm is characterized by the following first order condition

$$
P_{i t}=\left(\frac{\theta \mathbb{E}_{t}\left(\Phi_{i t}\left(\Psi_{i t}\left(\kappa M_{t}\right)^{\frac{1}{\gamma}} P_{t}^{\theta-\frac{1}{\gamma}}\right)^{\frac{1}{\alpha}} \mid \mathcal{I}_{i t}\right)}{\alpha(\theta-1) \mathbb{E}_{t}\left(\Psi_{i t}\left(\kappa M_{t}\right)^{\frac{1}{\gamma}-1} P_{t}^{\theta-\frac{1}{\gamma}} \mid \mathcal{I}_{i t}\right)}\right)^{\frac{1}{1+\frac{\theta}{\alpha}-\theta}}
$$

In order to solve for the firm's optimal pricing strategy, we conjecture that

(1) conditional on the firm's information, $\Phi_{i t}\left(\Psi_{i t}\left(\kappa M_{t}\right)^{\frac{1}{\gamma}} P_{t}^{\theta-\frac{1}{\gamma}}\right)^{\frac{1}{\alpha}}$ and $\Psi_{i t}\left(\kappa M_{t}\right)^{\frac{1}{\gamma}-1} P_{t}^{\theta-\frac{1}{\gamma}}$ are log-normally distributed, and

(2) conditional on a realization of the aggregate shock, the cross-sectional distribution of prices across firms is also log-normally distributed.

Taking $\operatorname{logs}$ to equation (10) we obtain ${ }^{25}$

$p_{i t}=$ const $_{1}+\frac{1}{1+\theta\left(\frac{1}{\alpha}-1\right)} \mathbb{E}_{i t}\left[\left(\frac{1}{\alpha}-1\right) \psi_{i t}+\phi_{i t}\right]+\mathbb{E}_{i t}\left[m_{t}\right]+\frac{\left(\theta-\frac{1}{\gamma}\right)\left(\frac{1}{\alpha}-1\right)}{1+\theta\left(\frac{1}{\alpha}-1\right)} \mathbb{E}_{i t}\left[p_{t}-m_{t}\right]$

\footnotetext{
${ }^{25}$ The natural logarithm of capital letters is denoted by small letters: $x=\log X$.
} 
where const $_{1}$ is a constant (all constants presented here on can be found in the Theoretical Appendix B) and to simplify notation we write $\mathbb{E}_{i t}[\cdot]$ to refer to $\mathbb{E}_{t}\left[\cdot \mid \mathcal{I}_{i t}\right]$. Similarly, we take $\operatorname{logs}$ to the equation defining the ideal price index to obtain

$$
p_{t}=\log \left(\left(\int_{0}^{1} \Psi_{i t} P_{i t}^{1-\theta} \mathrm{d} i\right)^{\frac{1}{1-\theta}}\right)=\text { const }_{2}+\int_{0}^{1} p_{i t} \mathrm{~d} i
$$

Notice that the firm's optimal price is increasing in the conditional expectation of both idiosyncratic shocks and increasing in the conditional expectation of money. Additionally, as long as $\theta>\gamma^{-1}$ the model exhibits pricing complementarities, i.e., optimal idiosyncratic price is increasing in the conditional expectation of the aggregate price.

\subsection{Firm's Information Structure}

In each period firms have access to idiosyncratic and aggregate signals. In the first place, each firm observes its total revenues $P_{i t} C_{i t}$ and the total wage bill $W_{i t} L_{i t}$ paid to its employees. This is equivalent to observing a demand signal $s_{i t}^{c}$ and a wage bill signal $s_{i t}^{w}$ :

$$
\begin{aligned}
& s_{i t}^{c}=\psi_{i t}+\frac{1}{\gamma} m_{t}+\left(\theta-\frac{1}{\gamma}\right) p_{t} \\
& s_{i t}^{w}=\phi_{i t}+m_{t}
\end{aligned}
$$

Firms also have access to a noise aggregate signal of the aggregate price level $s_{t}^{p}$ :

$$
s_{t}^{p}=p_{t}+\sigma_{p} \varepsilon_{t}^{p} \quad \varepsilon_{t}^{p} \sim N(0,1)
$$

We believe that this is a realistic assumption, since the level of the CPI is readily available from national statistics agencies and frequently used by agents to make economic decisions. The additional noise could be interpreted as pure measurement error or as an error that arises when agents focus on the national measures of the price level when the relevant information for their pricing decisions is the regional level of prices. ${ }^{26}$ The motivation to include this type of noise is much clear in our context, given that the policy change that we study corresponds to an increase in the variance of the noise $\sigma_{p} \cdot{ }^{27}$

In order to have information frictions in our model, we need to assume that contemporaneous signals become available after firms choose their prices. If the firm observed the contemporaneous signals before choosing the price, it would be able to set the full-information

\footnotetext{
${ }^{26}$ In this case, the distribution of such disturbances will probably not be iid normal.

${ }^{27}$ Furthermore, this type of informational friction (as opposed to the sticky-price-type information friction à la Mankiw and Reis (2002)) is supported by the empirical analysis of survey forecast data from US professional forecasters by Coibion and Gorodnichenko (2012).
} 
price:

$$
p_{i t}=\text { const }_{1}+\frac{\left(\frac{1}{\alpha}-1\right)}{1+\theta\left(\frac{1}{\alpha}-1\right)} s_{i t}^{d}+\frac{1}{1+\theta\left(\frac{1}{\alpha}-1\right)} s_{i t}^{w}
$$

The firm's information set at the beginning of period $t$ is thus characterized by the following filtration:

$$
\mathcal{I}_{i t}=\left\{s_{i t-s}^{d}, s_{i t-s}^{w}, s_{t-s}^{p}\right\}_{s=1}^{\infty}
$$

Given this information set the firms will face a signal-extraction problem in which they will not be able to perfectly disentangle the realization of all aggregate and idiosyncratic shocks since the number of signals per period (three) is lower than the number of aggregate and idiosyncratic shocks (four).

\subsection{Solution}

We follow the solution method proposed by Hellwig and Venkateswaran (2009), which provides an approximate solution by assuming that the aggregate state of the economy becomes common knowledge after $T$ periods (which is allowed to be arbitrarily large, but finite). ${ }^{28}$ Then, the filtration $\mathcal{I}_{i t}$ is replaced by

$$
\hat{\mathcal{I}}_{i t}=\left\{s_{i t-s}^{d}, s_{i t-s}^{w}, s_{t-s}^{p}, \varepsilon_{i t-T-s}^{\Phi}, \varepsilon_{i t-T-s}^{\Psi}, \varepsilon_{t-T-s}^{m}, \varepsilon_{t-T-s}^{p}\right\}_{s=1}^{\infty} .
$$

With this filtration, the dimensionality of the signal extraction problem is reduced to a finite number of shocks. Before proceeding with the solution of the model we need to introduce some notation. Let $\varepsilon_{i t}^{x}$ denote the vector of innovations to the process $x$ that have occurred but not been fully revealed as of time $t$ :

$$
\begin{aligned}
\varepsilon_{i t}^{\Phi} & =\left(\varepsilon_{i t-1}^{\Phi}, \varepsilon_{i t-2}^{\Phi}, \ldots, \varepsilon_{i t-T}^{\Phi}\right) \\
\varepsilon_{i t}^{\Psi} & =\left(\varepsilon_{i t-1}^{\Psi}, \varepsilon_{i t-2}^{\Psi}, \ldots, \varepsilon_{i t-T}^{\Psi}\right) \\
\varepsilon_{t}^{m} & =\left(\varepsilon_{t-1}^{m}, \varepsilon_{t-2}^{m}, \ldots, \varepsilon_{t-T}^{m}\right) \\
\varepsilon_{t}^{p} & =\left(\varepsilon_{t-1}^{p}, \varepsilon_{t-2}^{p}, \ldots, \varepsilon_{t-T}^{p}\right)
\end{aligned}
$$

It is useful to decompose the optimal pricing decision of the firm into a common knowledge component and filtering component that depends on the unobserved innovations. Let $\Upsilon_{\boldsymbol{\Psi}} \equiv$ $\left(1, \rho_{\Psi}, \rho_{\psi}^{2}, \ldots, \rho_{\psi}^{T-1}\right), \Upsilon_{\boldsymbol{\Phi}} \equiv\left(1, \rho_{\Phi}, \rho_{\phi}^{2}, \ldots, \rho_{\phi}^{T-1}\right)$ and $\mathbf{1}=(1, \ldots, 1)$. Then we can write the

\footnotetext{
${ }^{28}$ In our quantitative analysis we will choose $T$ to be equal to 30 quarters.
} 
firm's optimal price as

$$
\begin{aligned}
p_{i t} & =\hat{p}_{i t}+\frac{\left(\frac{1}{\alpha}-1\right) \sigma_{\Psi} \rho_{\Psi}}{1+\theta\left(\frac{1}{\alpha}-1\right)} \boldsymbol{\Upsilon}_{\boldsymbol{\Psi}} \mathbb{E}_{i t}\left[\varepsilon_{i t}^{\Psi}\right]+\frac{\sigma_{\Phi} \rho_{\Phi}}{1+\theta\left(\frac{1}{\alpha}-1\right)} \boldsymbol{\Upsilon}_{\boldsymbol{\Phi}} \mathbb{E}_{i t}\left[\varepsilon_{i t}^{\Phi}\right] \\
& +\left(\frac{1+\frac{1}{\gamma}\left(\frac{1}{\alpha}-1\right)}{1+\theta\left(\frac{1}{\alpha}-1\right)}\right) \sigma_{m} \mathbf{1} \mathbb{E}_{i t}\left[\varepsilon_{t}^{m}\right]+\left(\frac{\left(\theta-\frac{1}{\gamma}\right)\left(\frac{1}{\alpha}-1\right)}{1+\theta\left(\frac{1}{\alpha}-1\right)}\right)\left(\mathbb{E}_{i t}\left[p_{t}\right]-\hat{p}_{t}\right)
\end{aligned}
$$

where the common knowledge component of the firm's price, $\hat{p}_{i t}$, is given by

$$
\hat{p}_{i t}=\text { const }_{3}+m_{t-T-1}+\frac{1}{1+\theta\left(\frac{1}{\alpha}-1\right)}\left(\left(\frac{1}{\alpha}-1\right) \rho_{\psi}^{T+1} \psi_{i t-T-1}+\rho_{\phi}^{T+1} \phi_{i t-T-1}\right)
$$

and the common knowledge component of the aggregate price, $\hat{p}_{t}$, is given by $\hat{p}_{t}=$ const $_{4}+$ $m_{t-T-1}$.

We conjecture that the aggregate price level will follow

$$
p_{t}=\hat{p}_{t}+\sigma_{m} k^{m} \varepsilon_{t}^{m}+\sigma_{p} k^{p} \varepsilon_{t}^{p}
$$

where $k^{x}=\left(k_{1}^{x}, k_{2}^{x}, \ldots, k_{T}^{x}\right)$ for $x=m, p$. This conjectured solution implies that aggregate prices fully reflect the common knowledge component, and that they react to innovations in the money supply and to the noise of the CPI signal according to $k^{m}$ and $k^{p}$, respectively. Using this conjecture the optimal price set by the firm is given by

$$
\begin{aligned}
p_{i t} & =\hat{p}_{i t}+\frac{\left(\frac{1}{\alpha}-1\right) \sigma_{\Psi} \rho_{\Psi}}{1+\theta\left(\frac{1}{\alpha}-1\right)} \Upsilon_{\Psi} \mathbb{E}_{i t}\left[\varepsilon_{i t}^{\Psi}\right]+\frac{\sigma_{\Phi} \rho_{\Phi}}{1+\theta\left(\frac{1}{\alpha}-1\right)} \Upsilon_{\boldsymbol{\Phi}} \mathbb{E}_{i t}\left[\varepsilon_{i t}^{\Phi}\right]+ \\
& \left(\frac{1+\frac{1}{\gamma}\left(\frac{1}{\alpha}-1\right)}{1+\theta\left(\frac{1}{\alpha}-1\right)}\right) \sigma_{m} 1 \mathbb{E}_{i t}\left[\varepsilon_{t}^{m}\right]+\left(\frac{\left(\theta-\frac{1}{\gamma}\right)\left(\frac{1}{\alpha}-1\right)}{1+\theta\left(\frac{1}{\alpha}-1\right)}\right)\left(\sigma_{m} k^{m} \mathbb{E}_{i t}\left[\varepsilon_{t}^{m}\right]+\sigma_{p} k^{p} \mathbb{E}_{i t}\left[\varepsilon_{t}^{p}\right]\right)
\end{aligned}
$$

This expression can be replaced in the definition of $p_{t}$ (equation (12)) to get

$$
\begin{aligned}
p_{t} & =\hat{p}_{t}+\frac{\left(\frac{1}{\alpha}-1\right) \sigma_{\Psi} \rho_{\Psi}}{1+\theta\left(\frac{1}{\alpha}-1\right)} \Upsilon_{\boldsymbol{\Psi}} \overline{\mathbb{E}}_{t}\left[\varepsilon_{i t}^{\Psi}\right]+\frac{\sigma_{\Phi} \rho_{\Phi}}{1+\theta\left(\frac{1}{\alpha}-1\right)} \Upsilon_{\boldsymbol{\Phi}} \overline{\mathbb{E}}_{t}\left[\varepsilon_{i t}^{\Phi}\right]+\left(\frac{\left(\theta-\frac{1}{\gamma}\right)\left(\frac{1}{\alpha}-1\right)}{1+\theta\left(\frac{1}{\alpha}-1\right)}\right) \sigma_{p} k^{p} \overline{\mathbb{E}}_{t}\left[\varepsilon_{t}^{p}\right] \\
& +\left(\left(\frac{1+\frac{1}{\gamma}\left(\frac{1}{\alpha}-1\right)}{1+\theta\left(\frac{1}{\alpha}-1\right)}\right) \mathbf{1}+\left(\frac{\left(\theta-\frac{1}{\gamma}\right)\left(\frac{1}{\alpha}-1\right)}{1+\theta\left(\frac{1}{\alpha}-1\right)}\right) k^{m}\right) \sigma_{m} \overline{\mathbb{E}}_{t}\left[\varepsilon_{t}^{m}\right]
\end{aligned}
$$


where $\overline{\mathbb{E}}_{t}[\cdot]=\int_{0}^{1} \mathbb{E}_{i t}[\cdot] \mathrm{d} i$. Then, according to our conjecture, the following condition must hold in equilibrium

$$
\begin{aligned}
\sigma_{m} k^{m} \varepsilon_{t}^{m}+\sigma_{p} k^{p} \varepsilon_{t}^{p} & =\frac{\left(\frac{1}{\alpha}-1\right) \sigma_{\Psi} \rho_{\Psi}}{1+\theta\left(\frac{1}{\alpha}-1\right)} \boldsymbol{\Upsilon}_{\boldsymbol{\Psi}} \overline{\mathbb{E}}_{t}\left[\varepsilon_{i t}^{\Psi}\right]+\frac{\sigma_{\Phi} \rho_{\Phi}}{1+\theta\left(\frac{1}{\alpha}-1\right)} \boldsymbol{\Upsilon}_{\boldsymbol{\Phi}} \overline{\mathbb{E}}_{t}\left[\varepsilon_{i t}^{\Phi}\right] \\
& +\left(\frac{\left(\theta-\frac{1}{\gamma}\right)\left(\frac{1}{\alpha}-1\right)}{1+\theta\left(\frac{1}{\alpha}-1\right)}\right) \sigma_{p} k^{p} \overline{\mathbb{E}}_{t}\left[\varepsilon_{t}^{p}\right] \\
& +\left(\left(\frac{1+\frac{1}{\gamma}\left(\frac{1}{\alpha}-1\right)}{1+\theta\left(\frac{1}{\alpha}-1\right)}\right) \mathbf{1}+\left(\frac{\left(\theta-\frac{1}{\gamma}\right)\left(\frac{1}{\alpha}-1\right)}{1+\theta\left(\frac{1}{\alpha}-1\right)}\right) k^{m}\right) \sigma_{m} \overline{\mathbb{E}}_{t}\left[\varepsilon_{t}^{m}\right]
\end{aligned}
$$

This equation defines the equilibrium values of $k^{m}$ and $k^{p}$, which are obtained by computing the expectations that appear in the right hand side. This is achieved by exploiting the information structure that we defined above and the simplifying assumption that the relevant information eventually becomes common knowledge to all the firms.

Let $\boldsymbol{s}_{i t}^{x}=\left(s_{i t-1}^{x}, s_{i t-2}^{x}, \ldots, s_{i t-T}^{x}\right)$ denote the vector of signals of type $x$. It will become useful to also decompose the firm's signals into a common knowledge component and a filtering component:

$$
\begin{aligned}
\boldsymbol{s}_{i t}^{c} & =\hat{\boldsymbol{s}}_{i t}^{c}+\sigma_{\Psi} \mathcal{T}\left(\Upsilon_{\Psi}\right) \varepsilon_{i t}^{\Psi}+\sigma_{m}\left(\frac{1}{\gamma} \mathcal{T}(\mathbf{1})+\left(\theta-\frac{1}{\gamma}\right) \mathcal{T}\left(\tilde{k}^{m}\right)\right) \varepsilon_{t}^{m}+\sigma_{p}\left(\theta-\frac{1}{\gamma}\right) \mathcal{T}\left(\tilde{k}^{p}\right) \\
\boldsymbol{s}_{i t}^{w} & =\hat{\boldsymbol{s}}_{i t}^{w}+\sigma_{\Phi} \mathcal{T}\left(\Upsilon_{\Phi}\right) \varepsilon_{i t}^{\Phi}+\sigma_{m} \mathcal{T}(\mathbf{1}) \varepsilon_{t}^{m} \\
\boldsymbol{s}_{t}^{p} & =\hat{\boldsymbol{s}}_{t}^{p}+\sigma_{m} \mathcal{T}\left(\tilde{k}^{m}\right) \boldsymbol{\varepsilon}_{t}^{m}+\sigma_{p}\left(\mathcal{T}\left(\tilde{k}^{p}\right)+I\right) \boldsymbol{\varepsilon}_{t}^{p}
\end{aligned}
$$

where $\mathcal{T}(v)$ is an upper triangular matrix that includes the first components of the vector $v$, i.e.

$$
\mathcal{T}(v)=\left[\begin{array}{cccc}
v_{1} & v_{2} & \cdots & v_{T} \\
0 & v_{1} & \cdots & v_{T-1} \\
\vdots & \vdots & \ddots & \vdots \\
0 & 0 & \cdots & v_{1}
\end{array}\right]
$$

and $\hat{\boldsymbol{s}}_{i t}^{x}$ denotes the common knowledge component of signals of type $x$ (see the Theoretical Appendix B for their expression). Given the distributional assumptions made about the idiosyncratic and aggregate processes, the vector $\left(\varepsilon_{t}^{m}, \varepsilon_{t}^{p}, \varepsilon_{i t}^{\psi}, \boldsymbol{\varepsilon}_{i t}^{\phi}, \boldsymbol{s}_{i t}^{c}, \boldsymbol{s}_{i t}^{w}, \boldsymbol{s}_{t}^{p}\right)$ is jointly normally distributed and therefore we can use properties of the multivariate normal distribution to compute the conditional expectations. These expectations are summarized by the following result and corollary: 
RESULT 1. The expectation of the innovations conditional on the firm-specific information set is given by

$$
\mathbb{E}_{i t}\left[\begin{array}{c|c}
\varepsilon_{t}^{m} & \\
\boldsymbol{\varepsilon}_{t}^{p} & \\
\boldsymbol{\varepsilon}_{i t}^{\psi} & \hat{\mathcal{I}}_{i t} \\
\boldsymbol{\varepsilon}_{i t}^{\phi} &
\end{array}\right]=\left[\begin{array}{c}
\Delta_{1}^{\prime} \\
\Delta_{2}^{\prime} \\
\Delta_{3}^{\prime} \\
\Delta_{4}^{\prime}
\end{array}\right] \Delta^{-1}\left[\begin{array}{c}
\boldsymbol{s}_{i t}^{c}-\hat{\boldsymbol{s}}_{i t}^{c} \\
\boldsymbol{s}_{i t}^{w}-\hat{\boldsymbol{s}}_{i t}^{w} \\
\boldsymbol{s}_{t}^{p}-\hat{\boldsymbol{s}}_{t}^{p}
\end{array}\right]
$$

where

$$
\begin{gathered}
\Delta_{1}=\sigma_{m}\left[\begin{array}{c}
\frac{1}{\gamma} \mathcal{T}(\mathbf{1})+\left(\theta-\frac{1}{\gamma}\right) \mathcal{T}\left(\tilde{k}^{m}\right) \\
\mathcal{T}(\mathbf{1}) \\
\mathcal{T}\left(\tilde{k}^{m}\right)
\end{array}\right] \quad \Delta_{2}=\sigma_{p}\left[\begin{array}{c}
\left(\theta-\frac{1}{\gamma}\right) \mathcal{T}\left(\tilde{k}^{p}\right) \\
0 \\
\mathcal{T}\left(\tilde{k}^{p}\right)+I
\end{array}\right] \\
\Delta_{3}=\sigma_{\Psi}\left[\begin{array}{c}
\mathcal{T}\left(\Upsilon_{\Psi}\right) \\
0 \\
0
\end{array}\right] \quad \Delta_{4}=\sigma_{\Phi}\left[\begin{array}{c}
0 \\
\mathcal{T}\left(\Upsilon_{\Phi}\right) \\
0
\end{array}\right]
\end{gathered}
$$

and $\Delta=\Delta_{1} \Delta_{1}^{\prime}+\Delta_{2} \Delta_{2}^{\prime}+\Delta_{3} \Delta_{3}^{\prime}+\Delta_{4} \Delta_{4}^{\prime}$.

Corollary 1.

$$
\overline{\mathbb{E}}_{t}\left[\begin{array}{c|c}
\varepsilon_{t}^{m} & \\
\varepsilon_{t}^{p} & \\
\boldsymbol{\varepsilon}_{i t}^{\psi} & \hat{\mathcal{I}}_{i t} \\
\varepsilon_{i t}^{\phi} &
\end{array}\right]=\left[\begin{array}{c}
\Delta_{1}^{\prime} \\
\Delta_{2}^{\prime} \\
\Delta_{3}^{\prime} \\
\Delta_{4}^{\prime}
\end{array}\right] \Delta^{-1}\left(\Delta_{1} \varepsilon_{t}^{m}+\Delta_{2} \varepsilon_{t}^{p}\right)
$$

The corollary follows from the fact that $\int_{0}^{1} \varepsilon_{i t}^{\Psi} \mathrm{d} i=\int_{0}^{1} \varepsilon_{i t}^{\Phi} \mathrm{d} i=0$.

Replacing these results in the equilibrium condition (17) we obtain the following system of equations that form the fixed point that defines the equilibrium of the model:

$$
\begin{aligned}
k^{m} & =\frac{1}{\sigma_{m}\left(1+\theta\left(\frac{1}{\alpha}-1\right)\right)}\left\{\left(\frac{1}{\alpha}-1\right) \sigma_{\Psi} \rho_{\Psi} \Upsilon_{\Psi} \Delta_{3}^{\prime}+\sigma_{\Phi} \rho_{\Phi} \Upsilon_{\Phi} \Delta_{4}^{\prime}+\left(\theta-\frac{1}{\gamma}\right)\left(\frac{1}{\alpha}-1\right) \sigma_{p} k^{p} \Delta_{2}^{\prime}\right. \\
& \left.+\left(1+\frac{1}{\gamma}\left(\frac{1}{\alpha}-1\right)\right) 1 \sigma_{m} \Delta_{1}^{\prime}\right\} \Delta^{-1} \Delta_{1}\left[I-\left(\frac{\left(\theta-\frac{1}{\gamma}\right)\left(\frac{1}{\alpha}-1\right)}{1+\theta\left(\frac{1}{\alpha}-1\right)}\right) \Delta_{1}^{\prime} \Delta^{-1} \Delta_{1}\right]^{-1} \\
k^{p} & =\frac{1}{\sigma_{p}\left(1+\theta\left(\frac{1}{\alpha}-1\right)\right)}\left\{\left(\left(1+\frac{1}{\gamma}\left(\frac{1}{\alpha}-1\right)\right) \mathbf{1}+\left(\theta-\frac{1}{\gamma}\right)\left(\frac{1}{\alpha}-1\right) k^{m}\right) \sigma_{m} \Delta_{1}^{\prime}\right. \\
& \left.+\left(\frac{1}{\alpha}-1\right) \sigma_{\Psi} \rho_{\Psi} \Upsilon_{\Psi} \Delta_{3}^{\prime}+\sigma_{\Phi} \rho_{\Phi} \Upsilon_{\boldsymbol{\Phi}} \Delta_{4}^{\prime}\right\} \Delta^{-1} \Delta_{2}\left[I-\left(\frac{\left(\theta-\frac{1}{\gamma}\right)\left(\frac{1}{\alpha}-1\right)}{1+\theta\left(\frac{1}{\alpha}-1\right)}\right) \Delta_{2}^{\prime} \Delta^{-1} \Delta_{2}\right]^{-1}
\end{aligned}
$$


The solution of the model is closed by finding the vectors $k^{m}$ and $k^{p}$ that satisfy these equations. Since this system of equations is highly nonlinear in $k^{m}$ and $k^{p}$ closed-form solutions are not available, but the model can be still solved numerically.

Next we analyze how aggregate shocks affect the dynamics of aggregate prices by examining its impulse response functions. Given our assumption about the money process, a money innovation produces a permanent effect on prices as depicted in Figure (6a). The price adjustment is gradual though, which reflects money non-neutrality. Since firms cannot tell apart the nature of the shock, they assign a positive probability to the shock being idiosyncratic. The optimal reaction to an idiosyncratic shock is different from the optimal reaction to a money shock given that idiosyncratic shocks die out and money shocks are permanent. ${ }^{29}$ Therefore, the optimal reaction of firms is to adjust prices to somewhere in between. As time goes by firms eventually learn the nature of the shock and increase prices until they reach full adjustment.

A more novel result is shown in Figure (6b). Information innovations to the reporting of the CPI can affect aggregate prices and thus equilibrium allocations. Immediately after the shock occurs firms cannot tell the exact nature of it: a high aggregate signal of the CPI can either be due to a money shock or to a noise in the reporting of the CPI. The optimal reaction of the firm is to adjust prices after they observe a high CPI signal and if subsequent periods give low reports of the CPI they gradually infer it was a reporting noise and undo the original price increase.

Using Result 1 to solve for the conditional expectations in equation (16) we can express idiosyncratic prices as a linear combination of idiosyncratic and aggregate signals

$$
\begin{aligned}
p_{i t} & =\hat{p}_{i t}+\left\{\frac{\left(\frac{1}{\alpha}-1\right) \sigma_{\Psi} \rho_{\Psi}}{1+\theta\left(\frac{1}{\alpha}-1\right)} \boldsymbol{\Upsilon}_{\boldsymbol{\Psi}} \Delta_{3}^{\prime}+\frac{\sigma_{\Phi} \rho_{\Phi}}{1+\theta\left(\frac{1}{\alpha}-1\right)} \boldsymbol{\Upsilon}_{\boldsymbol{\Phi}} \Delta_{4}^{\prime}+\left(\frac{\left(\theta-\frac{1}{\gamma}\right)\left(\frac{1}{\alpha}-1\right)}{1+\theta\left(\frac{1}{\alpha}-1\right)}\right) \sigma_{p} k^{p} \Delta_{2}^{\prime}\right. \\
& \left.+\left(\left(\frac{1+\frac{1}{\gamma}\left(\frac{1}{\alpha}-1\right)}{1+\theta\left(\frac{1}{\alpha}-1\right)}\right) \mathbf{1}+\left(\frac{\left(\theta-\frac{1}{\gamma}\right)\left(\frac{1}{\alpha}-1\right)}{1+\theta\left(\frac{1}{\alpha}-1\right)}\right) k^{m}\right) \sigma_{m} \Delta_{1}^{\prime}\right\} \Delta^{-1} \boldsymbol{s}_{i t} \\
& \equiv \hat{p}_{i t}+\Omega \boldsymbol{s}_{i t}
\end{aligned}
$$

where

\footnotetext{
${ }^{29}$ How much will the optimal reaction differ will depend on the persistence parameters of idiosyncratic shocks, $\rho_{\phi}, \rho_{\psi}$.
} 
Figure 6. IRF on Aggregate Prices

(A) Price Effect of Money Innovations

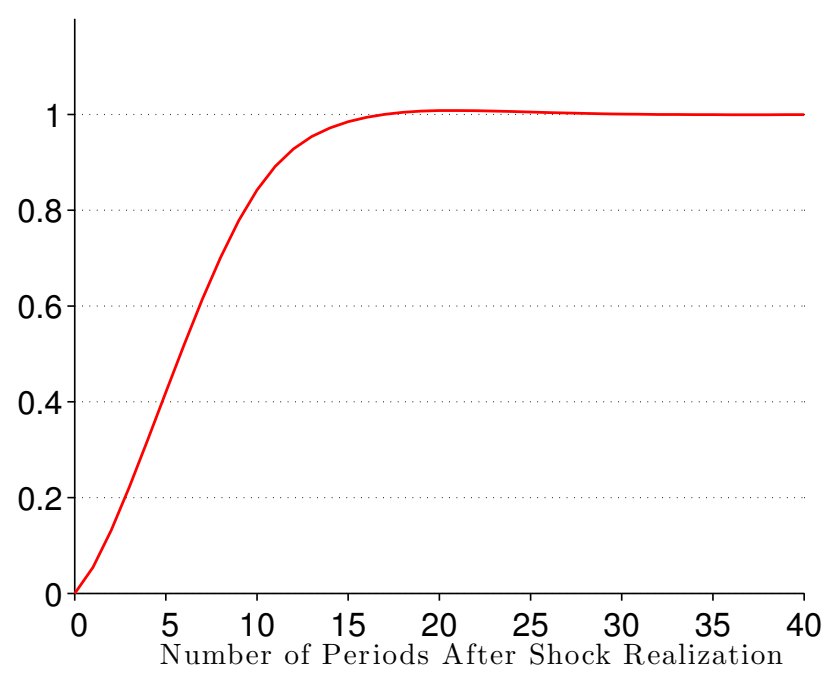

(B) Price Effect of CPI Innovations

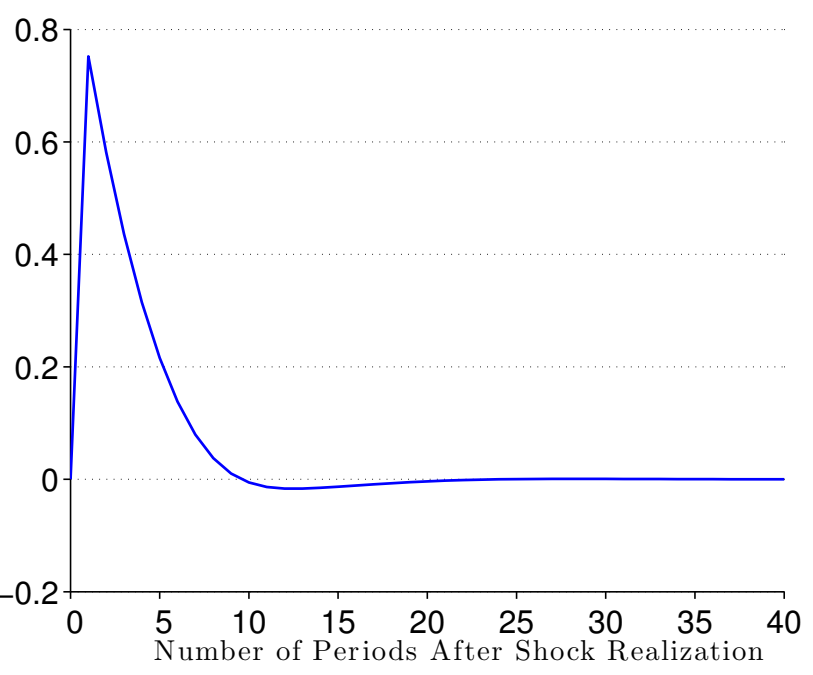

Notes: These graphs show the response over time of aggregate prices to an innovation of one at period zero.

$$
\boldsymbol{s}_{i t} \equiv\left[\begin{array}{c}
\boldsymbol{s}_{i t}^{c}-\hat{\boldsymbol{s}}_{i t}^{c} \\
\boldsymbol{s}_{i t}^{w}-\hat{\boldsymbol{s}}_{i t}^{w} \\
\boldsymbol{s}_{t}^{p}-\hat{\boldsymbol{s}}_{t}^{p}
\end{array}\right]
$$

Figure (7) plots the weights associated to the three signals used to set idiosyncratic prices. As it can be seen most of the weight is placed on recent signals since these are better predictors of contemporaneous innovations. However, some positive weight is placed in past signals. The reason is that in order to set prices firms not only need to form expectations about current aggregate and idiosyncratic shocks but also about past aggregate shocks since these affect current aggregate prices.

\subsection{Price Dispersion and Uncertainty About Inflation}

In this section we ask the model how price dispersion is affected when uncertainty about the level of the aggregate price increases and compare the model's predictions with our empirical results obtained in Section 3. Once the values of $k_{m}, k_{p}$ are obtained we can obtain analytic expressions for the cross-sectional price dispersion which are summarized in the following result. 
Figure 7. Bayesian Weights on Signals
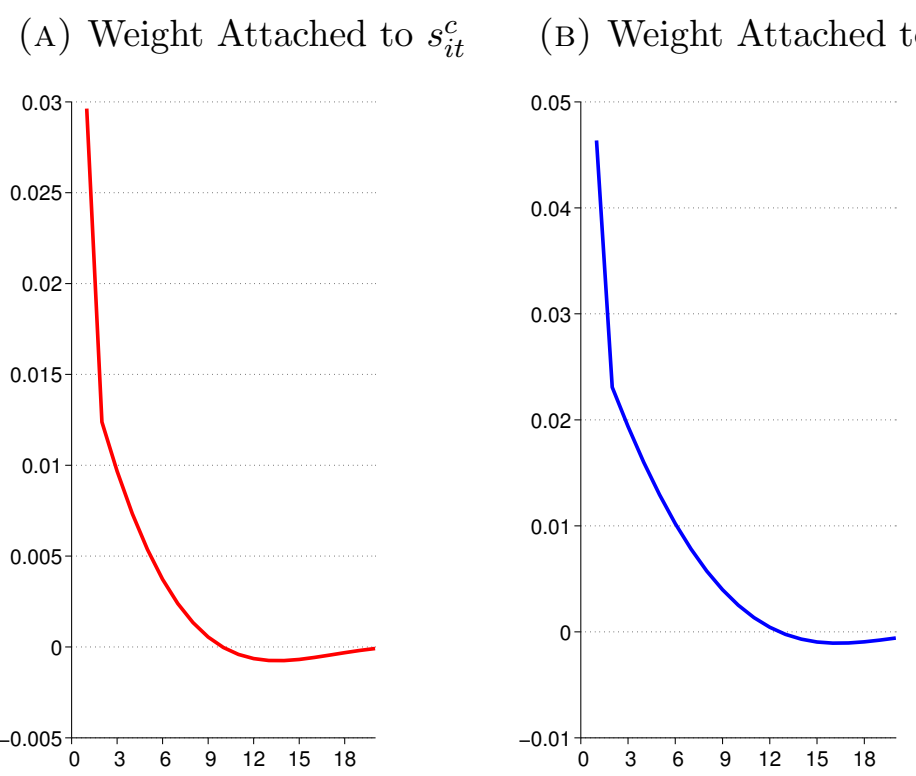

(c) Weight Attached to $s_{t}^{p}$

Notes: These graph show the weights attached to each component of $\boldsymbol{s}_{i t}$ as a function of the number of period since a signal was first observed

\section{RESUlT 2.}

$$
\begin{aligned}
\operatorname{var}^{i}\left(p_{i t}\right) & =\left(\frac{1}{1+\theta\left(\frac{1}{\alpha}-1\right)}\right)^{2}\left(\left(\frac{1}{\alpha}-1\right)^{2}\left(\rho_{\psi}^{T+1}\right)^{2} \operatorname{var}^{i}\left(\psi_{i t-T-1}\right)+\left(\rho_{\phi}^{T+1}\right)^{2} \operatorname{var}^{i}\left(\phi_{i t-T-1}\right)\right) \\
& +\Omega\left[\begin{array}{ccc}
\sigma_{\Psi}^{2} \mathcal{T}\left(\Upsilon_{\Psi}\right) \mathcal{T}\left(\Upsilon_{\Psi}\right)^{\prime} & 0 & 0 \\
0 & \sigma_{\Phi}^{2} \mathcal{T}\left(\Upsilon_{\Phi}\right) \mathcal{T}\left(\Upsilon_{\Phi}\right)^{\prime} & 0 \\
0 & 0 & 0
\end{array}\right] \Omega^{\prime}
\end{aligned}
$$

Coef $\operatorname{Var}^{i}\left(p_{i t}\right)=\left(\exp \left(\operatorname{var}^{i}\left(p_{i t}\right)\right)-1\right)^{1 / 2}$

The increase in uncertainty about the level of inflation is mapped in the model with an increase in the variance of the noise of the aggregate signal of prices $\sigma_{p}$. As shown in Figure (8) the model predicts that price dispersion is increasing in $\sigma_{p}$. The reason is that, faced with a noisier signal of aggregate prices, firms optimally perform Bayesian updates on the weights of each signal to set their prices. Since the aggregate signal of prices is noisier, they increase the weights attached to their idiosyncratic signals of demand and wages and reduce their weight attached to the aggregate signal, as shown in Figure (9). Given that idiosyncratic signals have cross-sectional dispersion this translates into higher cross-sectional dispersion of prices. As $\sigma_{p}$ increases the associated increase in price dispersion lowers. In 
fact, as $\sigma_{p} \rightarrow \infty$ the signal of aggregate prices becomes uninformative and price dispersion converges to a level in which firms only use their idiosyncratic signals to set prices.

FiguRe 8. Effect of Uncertainty About Inflation on Price Dispersion

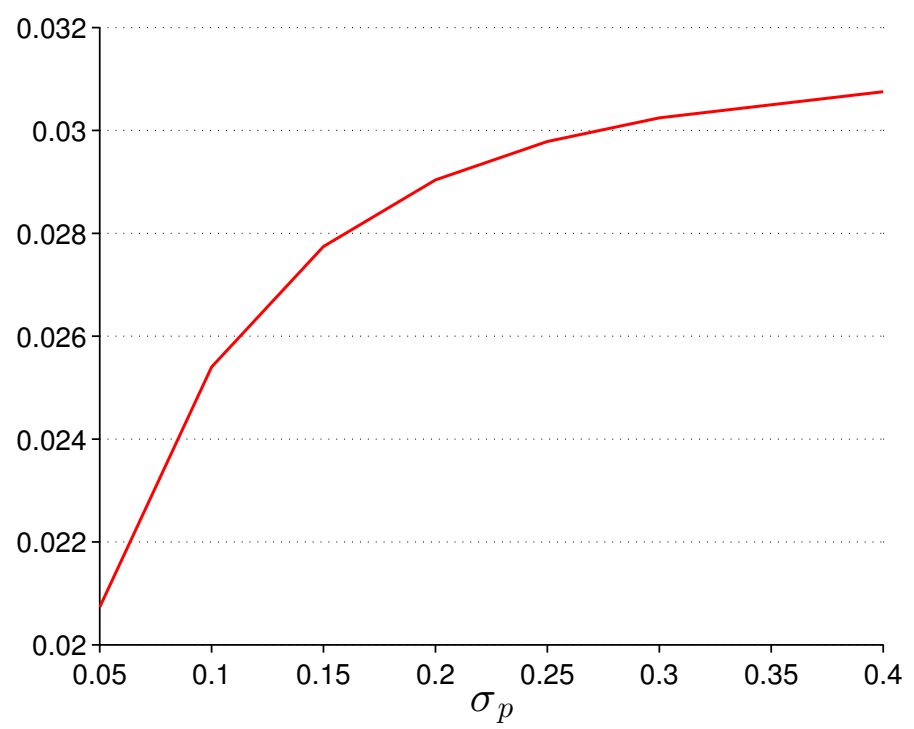

Notes: This graph shows the response of price dispersion, measured as the standard deviation of log prices, as a function of the standard deviation of the noise component of the aggregate signal of the aggregate price level $p_{t}$.

FiguRE 9. Weights on Signals: The Effect of Uncertainty About Inflation

(A) Weight Attached to $s_{i t}^{c}$

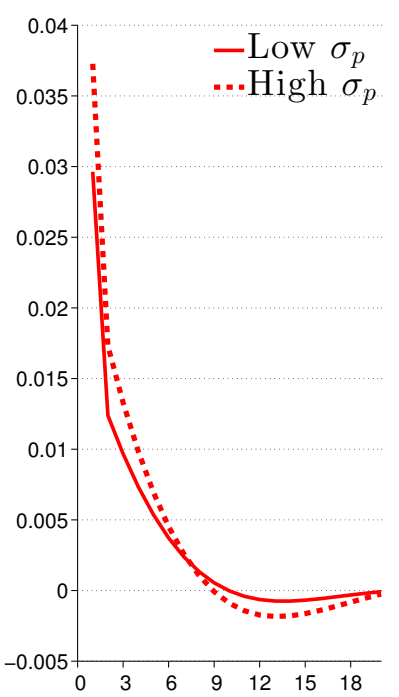

(B) Weight Attached to $s_{i t}^{w}$

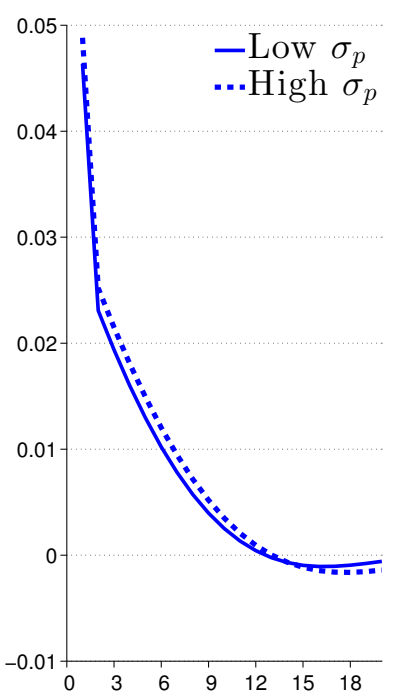

(C) Weight Attached to $s_{t}^{p}$

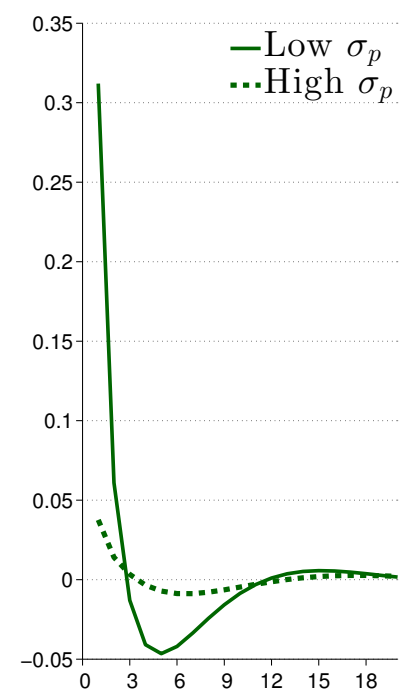

Notes: These graph show the weights attached to each component of $\boldsymbol{s}_{i t}$ as a function of the number of period since a signal was first observed, for two values of the standard standard deviation of the noise component of the aggregate signal of the aggregate price level $p_{t}$. 


\section{Quantitative Analysis}

\subsection{Calibration and Estimation}

Our model is parametrized by preference parameters $(\beta, \gamma, \theta)$, productivity parameter $\alpha$, four parameters that regulate the idiosyncratic processes $\left(\rho_{\Psi}, \sigma_{\Psi}, \rho_{\Phi}, \sigma_{\Phi}\right)$, parameters of the money supply process $\left(\mu, \sigma_{m}\right)$ and the dispersion of the noisy signal of the aggregate price level $\sigma_{p}$. The calibrated parameters are summarized in Table (7). In order to match an annual interest rate of $4 \%$ we choose $\beta=0.99$. The risk aversion parameter is set at a standard value found in the previous literature $\gamma=2$. We fix $\theta=10$, which is a relatively high number (although Reis (2009) chooses a value of 11), but since the empirical analysis was carried out at different levels of good classifications we will explore the sensitivity of the results of the model to changes in this parameter. For the parameter governing the marginal productivity of labor we choose $\alpha=0.5$, which is close to the value used in Burstein and Hellwig (2008).

TABLE 7. Calibrated Parameters

\begin{tabular}{|c|c|c|}
\hline Parameter & Value & Comments \\
\hline \multicolumn{3}{|c|}{ From Literature } \\
\hline$\beta$ & 0.99 & \\
\hline$\gamma$ & 2 & \\
\hline$\theta$ & 10 & \\
\hline$\alpha$ & 0.5 & \\
\hline$\rho_{\Psi}$ & 0.125 & Burstein and Hellwig (2008) \\
\hline$\sigma_{\Psi}$ & 0.449 & Burstein and Hellwig (2008) \\
\hline \multicolumn{3}{|l|}{ Estimated } \\
\hline$\rho_{\Phi}$ & 0.605 & Estimated with wage data \\
\hline$\sigma_{\Phi}$ & 0.591 & Estimated with wage data \\
\hline \multicolumn{3}{|l|}{ Calibrated } \\
\hline$\mu$ & 0.034 & Average Inflation 2003-11 \\
\hline$\sigma_{m}$ & 0.052 & Standard Deviation of Inflation 2003-11 \\
\hline$\sigma_{p}^{l o w}$ & 0.025 & \\
\hline$\sigma_{p}^{h i g h}$ & 0.400 & Jump in Observed Price Dispersion \\
\hline
\end{tabular}


In order to calibrate the process for the idiosyncratic labor costs we make use of the first order condition (8) which can be expressed (in logs) as

$$
w_{i t}=\log (\kappa)+\phi_{i t}+m_{t}
$$

Lagging this equation for one period, multiplying it by $\rho_{\Phi}$ and subtracting it from the previous equation we get

$$
w_{i t}=\log (\kappa)\left(1-\rho_{\Phi}\right)+\rho_{\Phi} w_{i t-1}+m_{t}-\rho_{\Phi} m_{t-1}+\sigma_{\Phi} \varepsilon_{i t}^{\Phi}
$$

Thus, the parameters of interest $\rho_{\Phi}$ and $\sigma_{\Phi}$ can be recovered by estimating the following equation

$$
w_{i t}=a_{1}+a_{2} w_{i t-1}+\mathbf{b} 1(t)+\sigma \nu_{i t}
$$

where $a_{2}$ is a consistent estimator of $\rho_{\Phi}$ and $\sigma$ is a consistent estimator for $\sigma_{\Phi}$. The variables $1(t)$ are indicator variables for period $t$ and capture the effects of the aggregate term $m_{t}-$ $\rho_{\Phi} m_{t-1}$. We estimate equation (18) using data from the Argentinean Household Survey (Encuesta Permanente de Hogares), which is a rotating survey following workers for two consecutive quarters. The estimation was done using data from 2003 to 2011 (we also computed estimations for the sample 2003 to 2006 to avoid including the effect that the policy might also have had on the wage setting process and results yield very similar point estimates). For this purpose we use data on (log) hourly wages for workers aged between 18 and 65 years old, that were employed in two consecutive quarters. The point estimates are presented in Table (7). The estimated values of the autoregressive coefficient and the standard deviation for the innovations are 0.605 and 0.591 , respectively.

The parameters governing the demand shock process are adapted from Burstein and Hellwig (2008) to account for the difference in the period length. In Burstein and Hellwig (2008) the process is specified on a monthly basis with serial correlation coefficient of 0.5 and standard deviation coefficient of 0.257. In our model one period is equivalent to one quarter, therefore, we adapt the coefficients ${ }^{30}$ to obtain a quarterly autocorrelation of 0.125

\footnotetext{
${ }^{30}$ Let $x_{t}$ be a monthly process $x_{t}=\rho_{x} x_{t-1}+\sigma \varepsilon_{t}$ and $w_{t}$ be the quarterly end-of-period observation of that process. Then

$$
\begin{aligned}
& w_{t}=\rho_{x}^{3} x_{t-3}+\sigma \varepsilon_{t}+\sigma \rho \varepsilon_{t-1}+\sigma \rho^{2} \varepsilon_{t-2} \\
& w_{t}=\rho_{w} w_{t-1}+\sigma_{w} u_{t}
\end{aligned}
$$
}


and a standard deviation of 0.449. The parameters of the money supply process are chosen to match the Argentinean average inflation rate (0.0333) and the standard deviation of inflation (0.0328) for the 2003-2011 period.

Finally, the standard deviations of the noise component of the aggregate signal are picked in order to match the jump in price dispersion of $18 \%$ that we estimated in section 3 . The calibrated change in $\sigma_{p}$ is quite large in magnitude, however it is hard to argue that it is unusually high given that this is one of the first papers that provides such estimates. Furthermore, this change in $\sigma_{p}$ corresponds to a regime switch from one in which firms attach some weight to the public signals about the CPI to one in which firms completely disregard the aggregate signal.

\subsection{Effects of an Increase in Uncertainty}

We use our calibrated model to compute for the transitional dynamics of the price dispersion and compare them to our empirical results. To solve for the transitional dynamics we need to solve for the vectors $k_{m}$ and $k_{p}$ for each of the periods of the transition from the steady state with $\sigma_{p}^{\text {low }}$ to the new steady state with $\sigma_{p}^{\text {high }}$. The derivation of the solution for the transitional dynamics can be found on Appendix B.2.

Figure (10) shows the empirical estimates from the flexible specification with semester specific dummies for Argentina and the transitional dynamics of the model's implied price dispersion. As it can be seen, the calibrated effect falls short of the point estimate empirical effect. We are unable to calibrate the full effect since the calibrated values of $\sigma_{p}^{\text {low }}$ and $\sigma_{p}^{\text {high }}$ are already too extreme and there is no more room to generate additional increase in price dispersion. ${ }^{31}$ An interesting point that comes out of this analysis is that the model's transitional dynamics of price dispersion reproduces the dynamics of our empirical estimates. Both of them exhibit a gradual increase of price dispersion at a decaying rate. These dynamics can be rationalized by our model. The optimal short-term reaction of firms to an increase in the noise of the CPI signal is not only to place more weight in their idiosyncratic signals but also to place more weight on past signals of the CPI, back when these were not where

$$
\begin{aligned}
w_{t-1} & =x_{t-3} & u_{t} & =\frac{\sigma \varepsilon_{t}+\sigma \rho \varepsilon_{t-1}+\sigma \rho^{2} \varepsilon_{t-2}}{\sigma+\rho \sigma+\rho^{2} \sigma} \\
\rho_{w} & =\rho_{x}^{3} & \sigma_{w} & =\sigma+\rho \sigma+\rho^{2} \sigma
\end{aligned}
$$

The adjustment for the quarterly average observation is similar although a little more involved.

${ }^{31}$ The fact that the model is unable to reproduce observed increase in cross-sectional dispersion in macroeconomic variables is also shared by other types of models with dispersed information (e.g. ?). 
contaminated by the high-variance noise. As time goes by, the latter become less useful as predictors of current economic shocks and therefore firms shift their weights to current idiosyncratic shocks even further and thus observed price dispersion increases.

Figure 10. Effect of Uncertainty About Inflation on Price Dispersion

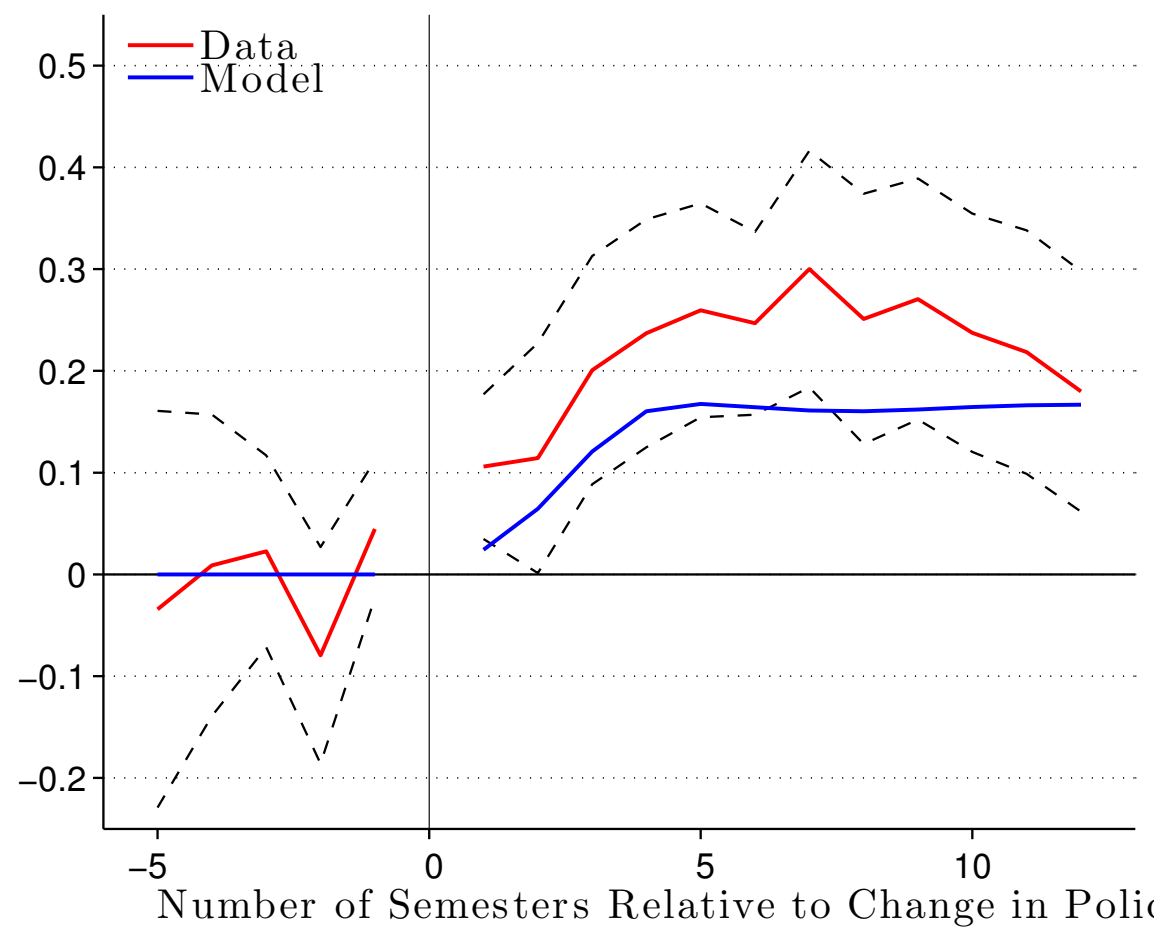

Notes: This graph compares the estimated effect of higher uncertainty about inflation obtained in the empirical analysis (red line with 95\% confidence interval in black) with the predictions obtained in our model (blue line). Since the period length in our model is a quarter, we take the average across quarters in order to compute the predicted effect on a six-months basis.

Next we investigate the effects that an increase in $\sigma_{p}$ has on aggregate variables, in particular aggregate consumption and labor. In order to have a better understanding of these effects we decompose aggregate consumption and labor in the following way

$$
C_{t}=\exp \left(\mathbb{E}^{i}\left(c_{i t}\right)+\frac{1}{2 \theta(\theta-1)} \operatorname{var}^{i}\left(\psi_{i t}\right)+\frac{(\theta-1)}{2 \theta} \operatorname{var}^{i}\left(c_{i t}\right)+\frac{1}{\theta} \operatorname{cov}\left(\psi_{i t}, c_{i t}\right)\right)
$$

and

$$
L_{t} \equiv \int_{0}^{1} \Phi_{i t} L_{i t} \mathrm{~d} i=\exp \left(\frac{1}{\alpha} \mathbb{E}^{i}\left(c_{i t}\right)+\frac{1}{2} \operatorname{var}^{i}\left(\phi_{i t}\right)+\frac{1}{2 \alpha^{2}} \operatorname{var}^{i}\left(c_{i t}\right)+\frac{1}{\alpha} \operatorname{cov}\left(\phi_{i t}, c_{i t}\right)\right)
$$


These decompositions show that aggregate consumption depends positively on the crosssectional average of consumption, the cross-sectional variance of the preference shocks, the cross-sectional dispersion of consumption and the covariance between the preference shocks and the quantities consumed of each variety. ${ }^{32}$ Aggregate labor depends on similar components, but instead of depending on moments related to the preference shocks it depends on moments related to the shocks to the disutility of labor. These equations describe the trade-off that exists in this economy. The cross-sectional mean and variance of consumption affects aggregate consumption and the disutility of labor positively. More interestingly, aggregate consumption depends positively on the correlation between the consumption of each variety and its corresponding taste shock and aggregate labor also depends positively on the correlation between the labor supply to each variety and its corresponding disutility of labor shock. Thus, the representative household would benefit from a positive and high $\operatorname{cov}\left(\psi_{i t}, c_{i t}\right)$ and a negative $\operatorname{cov}\left(\phi_{i t}, c_{i t}\right)$. However, both types of shocks are uncorrelated, which prevents having such correlations.

Table (8) shows the average aggregate consumption and labor over time, and the relevant moments that affect these aggregates, for each economy. These results are obtained by simulating each economy for 500 periods, in which the only shocks are monetary shocks (all moments related to the cross-sectional distribution across firms are computed analytically). We repeat this exercise 500 times and report the averages across simulations. In our calibrated economies, an increase in the variance of the noise of the aggregate signal reduces average consumption and increases aggregate labor. This result already suggests that the increase in the noise of the aggregate signal will be welfare reducing since it will imply higher labor without an associated increase in consumption. These effects are driven by changes in the cross-sectional mean and variance of (log) consumption, which are an order of magnitude larger to the observed changes in both covariances. Also, the coefficients attached to the first two moments of the cross-sectional distribution of consumption in the decomposition shown in equations (19) and (20) are much larger to the coefficients attached to the covariances. In order to further understand the mechanisms behind these results, we decompose the cross-sectional mean and variance of consumption on elements related to the

\footnotetext{
${ }^{32}$ The reason why the cross-sectional variance of consumption has a positive effect on aggregate consumption is that the distributional assumption of preference shocks implies that an increase in the dispersion of quantities translates into a higher cross-sectional average consumption due to the Jensen inequality.
} 
firms' pricing decisions

$$
\mathbb{E}^{i}\left(c_{i t}\right)=-\frac{\theta}{2(\theta-1)} \operatorname{var}^{i}\left(\psi_{i t}\right)-\frac{\theta(\theta-1)}{2} \operatorname{var}^{i}\left(p_{i t}\right)+\theta \operatorname{cov}\left(\psi_{i t}, p_{i t}\right)+\frac{1}{\gamma}\left(\log (\kappa)+m_{t}-p_{t}\right)
$$

and

$$
\operatorname{var}^{i}\left(c_{i t}\right)=\operatorname{var}^{i}\left(\psi_{i t}\right)+\theta^{2} \operatorname{var}^{i}\left(p_{i t}\right)-2 \theta \operatorname{cov}\left(\psi_{i t}, p_{i t}\right)
$$

In equations (21) and (22) the first term is unaffected by changes in uncertainty. The only relevant components are the cross-sectional variance of (log) prices, the covariances between preference shocks and prices, and the (log) real balances. The bottom section of Table (8) shows the effect of higher uncertainty on these moments. First, the analysis reveals that there are level effects on (log) real balances. An increase in $\sigma_{p}$ reduces real balances by $3.6 \%$ by generating a level effect on aggregate prices. This is an interesting result since it suggests that a government trying to hide the fact that inflation is increasing by affecting the amount of information available to the agents in the economy might exacerbate the original increase in prices. Similarly, for reasons discussed above, price dispersion across varieties increases. Both effects contribute to a decrease in the cross-sectional mean and an increase in the variance of $(\log )$ consumption. Despite the fact that their quantitative effect are of second order, the covariances of idiosyncratic prices and idiosyncratic shocks move in the right direction. When $\sigma_{p}$ increases, firms decrease the weight attached to the aggregate signal when forming expectation about the state of the economy. Since part of that weight goes to the idiosyncratic signals (the remaining goes to the common prior), which depend positively on both idiosyncratic shock, prices have a higher co-movement with preference shocks and shocks to the disutlity of labor.

\subsection{Welfare Effects}

We have established that the increase in uncertainty about inflation entails larger levels of price dispersion. Higher price dispersion in turn leads to a higher aggregate level of labor and a lower level of aggregate consumption which is unambiguously welfare reducing for households. In this section we quantify the welfare losses associated to the increase in uncertainty about inflation.

Define the welfare change to higher uncertainty about inflation, $\lambda^{P}$, as the percent change in the lifetime consumption stream required by an individual living in an economy with accurate signal of CPI (i.e., $\sigma_{p}=\sigma_{p}^{\text {low }}$ ) in order to be as well off as an individual living in 
TABLE 8. Real Effects of Higher Uncertainty

\begin{tabular}{lcc}
\hline \hline & $\sigma_{p}^{\text {low }}$ & $\sigma_{p}^{\text {high }}$ \\
\hline $\bar{C}$ & 0.6887 & 0.6765 \\
$\bar{L}$ & 2.9015 & 3.3776 \\
\hline$\overline{\mathbb{E}^{i}\left(c_{i t}\right)}$ & -0.5749 & -0.6191 \\
$\operatorname{var}^{i}\left(c_{i t}\right)$ & 0.3926 & 0.4518 \\
$\operatorname{cov}^{i}\left(\psi_{i t}, c_{i t}\right)$ & 0.1991 & 0.1928 \\
$\operatorname{cov}^{i}\left(\phi_{i t}, c_{i t}\right)$ & -0.1940 & -0.2000 \\
\hline$\overline{m_{t}-p_{t}}$ & 2.4205 & 2.3840 \\
$\operatorname{var}^{i}\left(p_{i t}\right)$ & 0.0020 & 0.0027 \\
$\operatorname{cov}^{i}\left(\psi_{i t}, p_{i t}\right)$ & 0.0006 & 0.0012 \\
$\operatorname{cov}^{i}\left(\phi_{i t}, p_{i t}\right)$ & 0.0194 & 0.0200 \\
\hline \hline
\end{tabular}

Notes: This table shows moments of aggregate variables and moments related to the cross-sectional distribution of $(\log )$ consumption and $(\log )$ prices across firms, obtained by simulating each economy for 500 periods, in which the only shocks are monetary shocks (all moments related to the cross-sectional distribution across firms are computed analytically and do not change across simulations). We repeat this exercise 500 times and report the averages across simulations. Variables with a bar denote the (average across simulations of the) average across time within simulations.

an economy where at date zero the CPI signal becomes noisier (i.e., $\sigma_{p}$ increases to $\sigma_{p}^{\text {high }}$ at $t=0) \cdot{ }^{33}$ Formally, $\lambda^{P}$ is implicitly given by

$$
\begin{array}{r}
\mathbb{E}\left(\sum_{t=0}^{\infty} \beta^{t}\left[\frac{C_{t}^{L}\left(1+\lambda^{P}\right)^{1-\gamma}}{1-\gamma}-\int_{0}^{1} \Phi_{i t} L_{i t}^{L} \mathrm{~d} i+\ln \left(\frac{M_{t}}{P_{t}^{L}}\right)\right]\right)= \\
\mathbb{E}\left(\sum_{t=0}^{\infty} \beta^{t}\left[\frac{C_{t}^{H^{1-\gamma}}}{1-\gamma}-\int_{0}^{1} \Phi_{i t} L_{i t}^{H} \mathrm{~d} i+\ln \left(\frac{M_{t}}{P_{t}^{H}}\right)\right]\right)
\end{array}
$$

where the superscript $L, H$ refer to allocations in economy with $\sigma_{p}^{\text {low }}, \sigma_{p}^{\text {high }}$, respectively. The underlying assumption under this exercise is that the change in the variance of the noise in the aggregate signal of the CPI is permanent. We also compute the welfare associated to a transitory change in the noise of the aggregate signal of prices. In particular, we define

\footnotetext{
${ }^{33}$ For simplicity of the calculations (given the high dimension of the state space) we compute the initial state as the state in which the past $T$ aggregate and idiosyncratic shocks are all at its unconditional mean zero.
} 
the welfare change to a transitory increase in uncertainty about the rate of inflation, $\lambda^{T}$, as the percent change in the lifetime consumption stream required by an individual living in an economy with $\sigma_{p}=\sigma_{p}^{\text {low }}$ to be as well off as an individual living in an economy where at date zero $\sigma_{p}$ increases to $\sigma_{p}^{\text {high }}$ and after 5 years it returns to $\sigma_{p}^{\text {low }}$.

Table (9) shows that the welfare costs of not providing an accurate measure of CPI are large. The representative household living in an economy with an accurate measure of CPI requires a decrease in consumption of $4.4 \%$ every period to be indifferent between living in an economy with a noisy signal of CPI and an economy with an accurate signal of CPI. Such high welfare costs are associated with lower aggregate consumption and labor, as previously described. As noted in Table (9), the increase in price dispersion of $17 \%$ that is due to the noisier public signal of CPI translates into a decrease of aggregate consumption of $1.8 \%$ and an increase of aggregate labor of $16 \%$. Welfare costs are reduced to an equivalent decrease in consumption every period of $2.7 \%$ when we consider the case of a transitory increase in $\sigma_{p}$ that after 5 years returns to its low value.

TABLE 9. Welfare Effects of an Increase in $\sigma_{p}$

\begin{tabular}{lccc}
\hline \hline & Baseline & & \\
& $\theta=10$ & $\theta=7$ & $\theta=4$ \\
\hline & & & \\
$\Delta$ Price Dispersion & $16.66 \%$ & $15.36 \%$ & $13.28 \%$ \\
$\Delta$ Agg. Consumption & $-1.77 \%$ & $-1.38 \%$ & $-0.84 \%$ \\
$\Delta$ Agg. Labor & $16.41 \%$ & $13.85 \%$ & $10.56 \%$ \\
& & & \\
$\Delta$ Welfare Permanent & $-4.42 \%$ & $-3.46 \%$ & $-2.18 \%$ \\
$\Delta$ Welfare Transitory & $-2.70 \%$ & $-2.04 \%$ & $-1.23 \%$ \\
\hline \hline
\end{tabular}

It is important to note that this exercise and our general theoretical framework assume an exogenous monetary policy that follows a particular stochastic process. Monetary shocks are shown to be more effective in the context of higher uncertainty about inflation. Therefore, our estimations of welfare costs can change if we consider the case with an optimal design of monetary policy. It is also worth considering the fact that our analysis is not subject to potential negative effects of releasing accurate public information. In particular, since in our setup the only object that provides aggregate endogenous information is the aggregate price level, a decrease in the variance of the noise of the signal of aggregate prices does not reduce 
the informational content of prices. This would happen if the disclosure of information was about the fundamental shocks in the economy (see Amador and Weill (2010)).

Finally, we perform sensitivity analysis of our welfare calculations by changing the elasticity of substitution between goods of different varieties $\theta$. We consider alternative values of $\theta=\{7,4\}$ which are values used in Golosov and Lucas (2007) and Klenow and Willis (2007), respectively, as shown in the last two columns of Table (9). The estimated welfare costs are lower as we consider lower values of $\theta$. The reason is that as we lower the elasticity of substitution between products the associated increase in price dispersion is lower and so is the decrease in consumption and the increase in labor, thus resulting in lower estimates of welfare costs.

Table (9) also reveals a positive relationship between the elasticity of substitution $\theta$ and its corresponding increase in price dispersion, which is qualitatively consistent with our empirical estimates of the effect of higher uncertainty about the inflation rate on price dispersion measured at different category levels. As shown in Table (6), the effect of higher uncertainty about inflation, measured as the percentage change of the coefficient of variation with respect to its pre-policy average, is increasing in the level of categories. Presumably, it can be thought that for higher levels of categories that provide more specific groupings of products, the elasticity of substitution between these products is higher, given that they are more homogeneous. Therefore, the estimated higher effect for more specific categories can be mapped into higher effects on price dispersion that the model predicts for higher elasticities of substitution.

\subsection{Effectiveness of Monetary Policy}

In this subsection we provide a quantitative analysis of the effectiveness of monetary policy when agents are more uncertain about the aggregate level of prices. To pursue this we analyze the dynamics of the reaction of prices and output to a money innovation in the steady state for two different economies, one with $\sigma_{p}^{\text {low }}$ and other with $\sigma_{p}^{\text {high }}$. Results are shown in Figure (11).

Monetary policy is more effective in the context of higher uncertainty about aggregate prices. ${ }^{34}$ In the economy with a precise measure of aggregate prices (solid line) prices react more quickly than in an economy with a noisy signal of aggregate prices (dashed line). In particular, two years after the realization of the monetary shock, prices adjust $80 \%$ of

\footnotetext{
${ }^{34}$ Our analysis of monetary policy corresponds to IRFs to monetary shocks using a given process of money supply. For an analysis of optimal monetary policy in the context of information frictions see Reis (2009).
} 
FiguRe 11. IRF of Money Innovations on Aggregate Prices

(A) Price Reaction

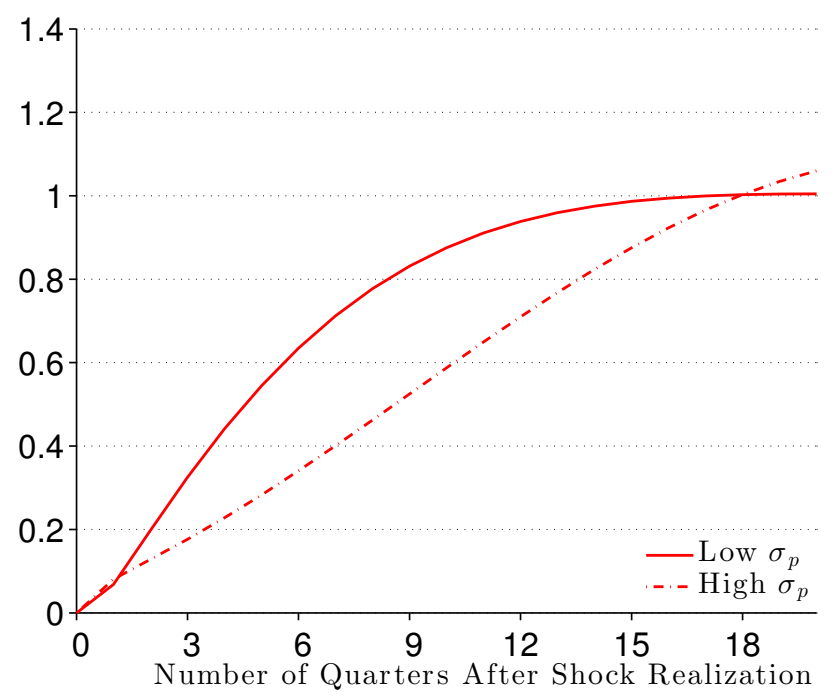

(B) Consumption Reaction

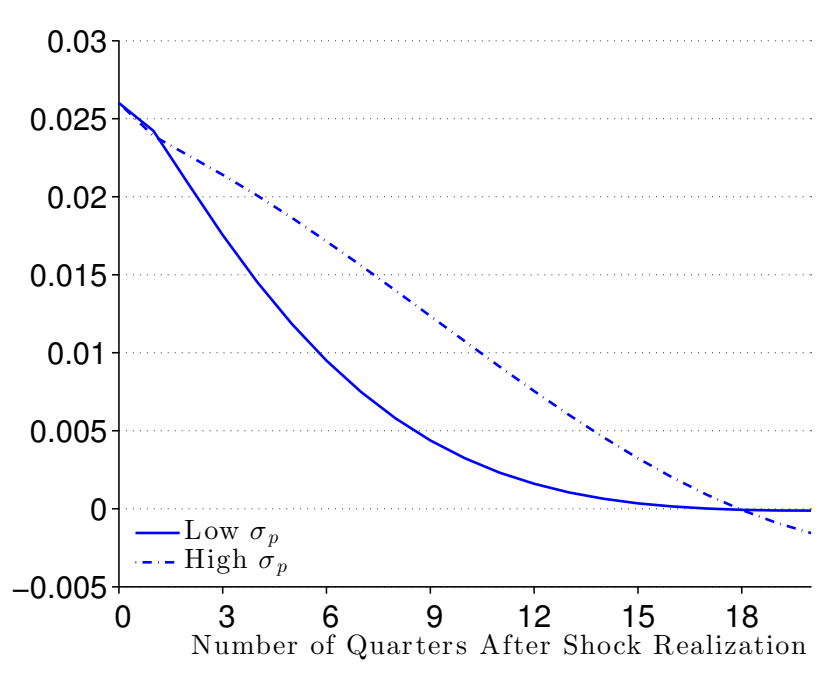

Notes: These graphs compare the response of aggregate prices and consumption to a monetary innovation of one at period zero, under the scenario of low uncertainty (solid lines) and high uncertainty (dashed lines).

the shock in the economy with $\sigma_{p}^{\text {low }}$ and only $50 \%$ in the economy with $\sigma_{p}^{h i g h}$. This $30 \%$ differential in the reaction of prices translates into a positive differential of $0.9 \%$ of output after two years in the economy with a noisy signal of aggregate prices with respect to the economy with an accurate CPI signal. The mechanism behind our result that monetary policy becomes more effective in the context of higher uncertainty about the inflation rate goes back to the idea that larger information frictions delay the response of prices.

\section{Conclusion}

Making use of a quasi-natural experiment in which economic agents lost access to relevant public information about the rate of inflation this paper estimates the effect of higher uncertainty about the level of inflation on price dispersion. Our difference-in-difference approach indicates that higher uncertainty about the levels of inflation are associated with higher observed price dispersion. We find the effect to be quite large in economics terms. The deterioration in the quality of public information about the levels of inflation in Argentina caused by the manipulation of official inflation statistics led to an increase in the coefficient of variation of prices of $18 \%$ with respect to its mean. Our results prove to be robust to different specifications that concern the choice of the dependent variable, the functional form 
of the estimated equation and the sample period of analysis. Additionally, we find the effect to be higher for products with higher degrees of substitutability.

We formulate a general equilibrium model of price setting tailored to analyze the episode of study and rationalize our empirical finding. The estimated increase in price dispersion can be attributed to firms using more idiosyncratic information (which has cross-sectional dispersion) as opposed to aggregate information about the macroeconomic state (which is not dispersed). Then we make use of our calibrated model to further explore the effects of higher uncertainty about inflation on the effectiveness of monetary policy and aggregate welfare and find rather striking results.

On the one hand, monetary policy is found to be more effective in the context of higher uncertainty about inflation. In other words, prices adjust slower to a monetary shock when firms are more unaware of the aggregate level of prices. It follows from this finding that an appropriate use of monetary policy can be better accompanied by less information about the aggregate macroeconomic state.

On the other hand, our welfare analysis points toward significant welfare losses associated to not reporting an accurate CPI measure. Higher uncertainty about the aggregate levels of prices leads to price dispersion, which in turn distorts the consumption basket of households. This last finding advocates for an adequate provision of public information about the level of prices and also about the macroeconomic state of the economy. 


\section{REFERENCES}

Alvarez, F., M. Gonzalez-Rozada, A. Neumeyer, and M. Beraja (2011a): "From Hyperinflation to Stable Prices: Argentina's Evidence on Menu Cost Models," manuscript, University of Chicago.

Alvarez, F. E., F. Lippi, and L. Paciello (2011b): "Optimal Price Setting With Observation and Menu Costs," Quarterly Journal of Economics, 126, 1909-1960.

Amador, M. And P.-O. Weill (2010): "Learning from Prices: Public Communication and Welfare," Journal of Political Economy, 118, 866-907.

Angeletos, G.-M. And J. LA'O (2009): "Incomplete Information, Higher-Order Beliefs and Price Inertia," Journal of Monetary Economics, 56, S19-S37.

Angeletos, G.-M. And A. Pavan (2004): "Transparency of Information and Coordination in Economies with Investment Complementarities," American Economic Review, 94, 91-98.

(2007): "Efficient Use of Information and Social Value of Information," Econometrica, $75,1103-1142$.

Baley, I. And J. Blanco (2013): "Learning to Price," manuscript, New York University. Bertrand, M., E. Duflo, and S. Mullainathan (2004): "How Much Should We Trust Differences-in-Differences Estimates?" Quarterly Journal of Economics, 119, 249-275.

Burstein, A. And C. Hellwig (2008): "Welfare Costs of Inflation in a Menu Cost Model," American Economic Review: Papers \&3 Proceedings, 98, 438-443.

Card, D. and A. B. Krueger (1994): "Minimum Wages and Employment: A Case Study of the Fast-Food Industry in New Jersey and Pennsylvania," American Economic Review, 84, 772-793.

Cavallo, A. (2013): "Online and Official Price Indexes: Measuring Argentina's Inflation," Journal of Monetary Economics, 60, 152-165.

Coibion, O. And Y. Gorodnichenko (2012): "What Can Survey Forecasts Tell Us about Information Rigidities?" Journal of Political Economy, 120, 116-159.

Golosov, M. And R. E. LuCAs, JR (2007): "Menu Costs and Phillips Curves," Journal of Political Economy, 115, 171-199.

Hellwig, C. and V. Venkateswaran (2009): "Setting the Right Prices for the Wrong Reasons," Journal of Monetary Economics, 56, S57-S77.

(2012): "Hayek Vs Keynes: Dispersed Information and Market Prices in a PriceSetting Model ," manuscript, Toulouse School of Economics. 
IMF (2008): World Economic Outlook, April 2008, Housing and the Business Cycle, International Monetary Fund.

Klenow, P. J. And J. L. Willis (2007): "Sticky Information and Sticky Prices," Journal of Monetary Economics, 54, 79-99.

LuCAS, R. E. J. (1972): "Expectations and the Neutrality of Money," Journal of Economic Theory, 4, 103-124.

Mankiw, N. G. And R. Reis (2002): "Sticky Information versus Sticky Prices: A Proposal to Replace the New Keynesian Phillips Curve," The Quarterly Journal of Economics, 117, $1295-1328$.

Morris, S. And H. S. Shin (2002): "Social Value of Public Information," American Economic Review, 92, 1521-1534.

Phelps, E. S. (1970): "Introduction: The New Microeconomics in Employment and Ination Theory," in Microeconomic Foundations of Employment and Ination Theory, ed. by E. S. Phelps, New York: Norton.

Reinsdorf, M. (1994): "New Evidence on the Relation Between Inflation and Price Dispersion," American Economic Review, 84, 720-731.

ReIs, R. (2006): "Inattentive Producers," The Review of Economic Studies, 73, 793-821.

- (2009): "Optimal Monetary Policy Rules in an Estimated Sticky-Information Model," American Economic Journal: Macroeconomics, 1, 1-28.

Van Hoomissen, T. (1988): "Price Dispersion and Inflation: Evidence from Israel," Journal of Political Economy, 1303-1314.

Vavra, J. (2014): "Inflation Dynamics and Time-Varying Volatility: New Evidence and an Ss Interpretation," Quarterly Journal of Economics, 129, 215-258.

Woodford, M. D. (2003): "Imperfect Common Knowledge and the Effects of Monetary Policy," in Knowledge, Information, and Expectations in Modern Macroeconomics: In Honor of Edmund S. Phelps, ed. by P. Aghion, R. Frydman, J. Stiglitz, and M. Woodford, Princeton Univ. Press. 


\section{Appendix A. Empirical Appendix}

\section{A.1. Description of the e-trade platform}

Figure A.1. Number of Publications over Time (in Thousands)

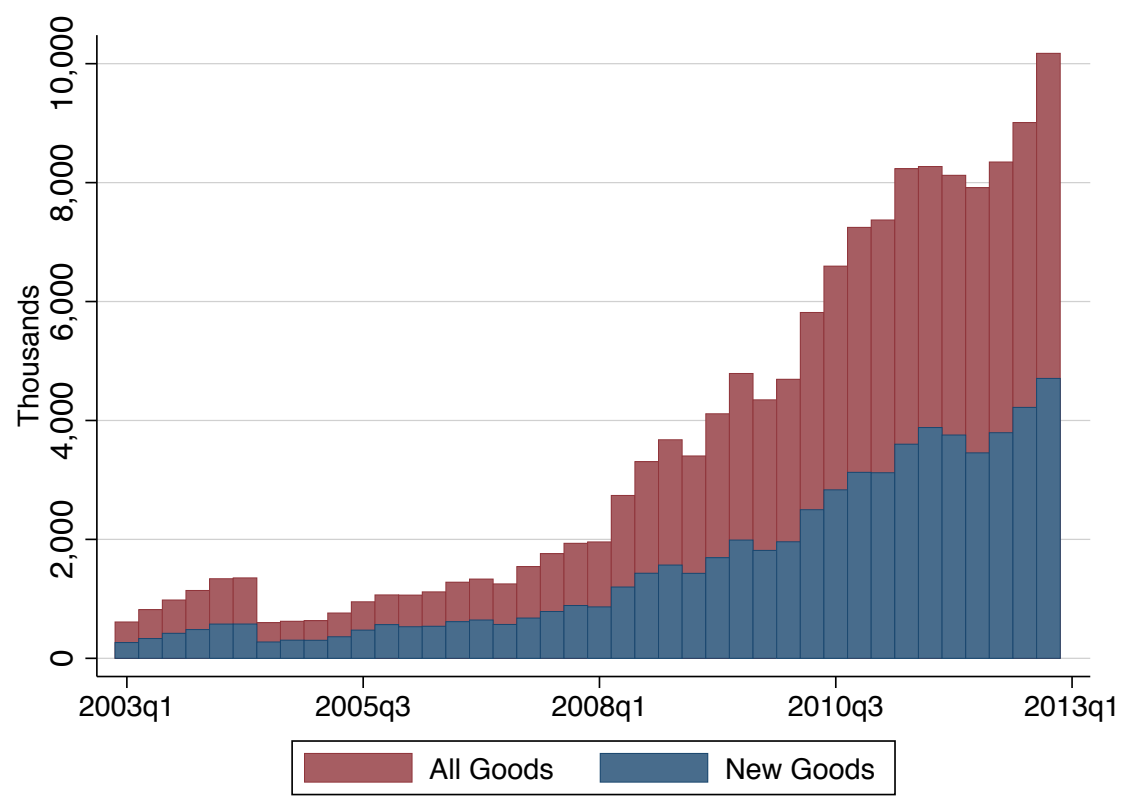

Figure A.2. Histogram of Quantities of New Goods Offered by Publication

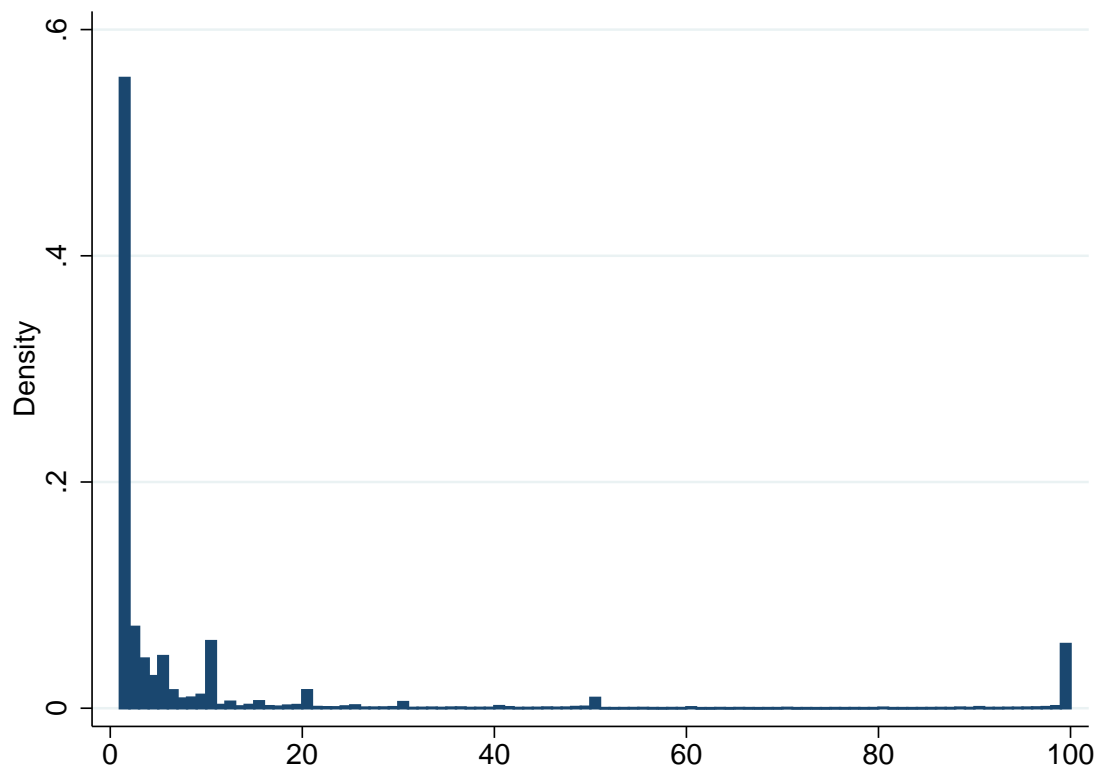


Figure A.3. Histogram of Number of Publications of New Goods by Seller

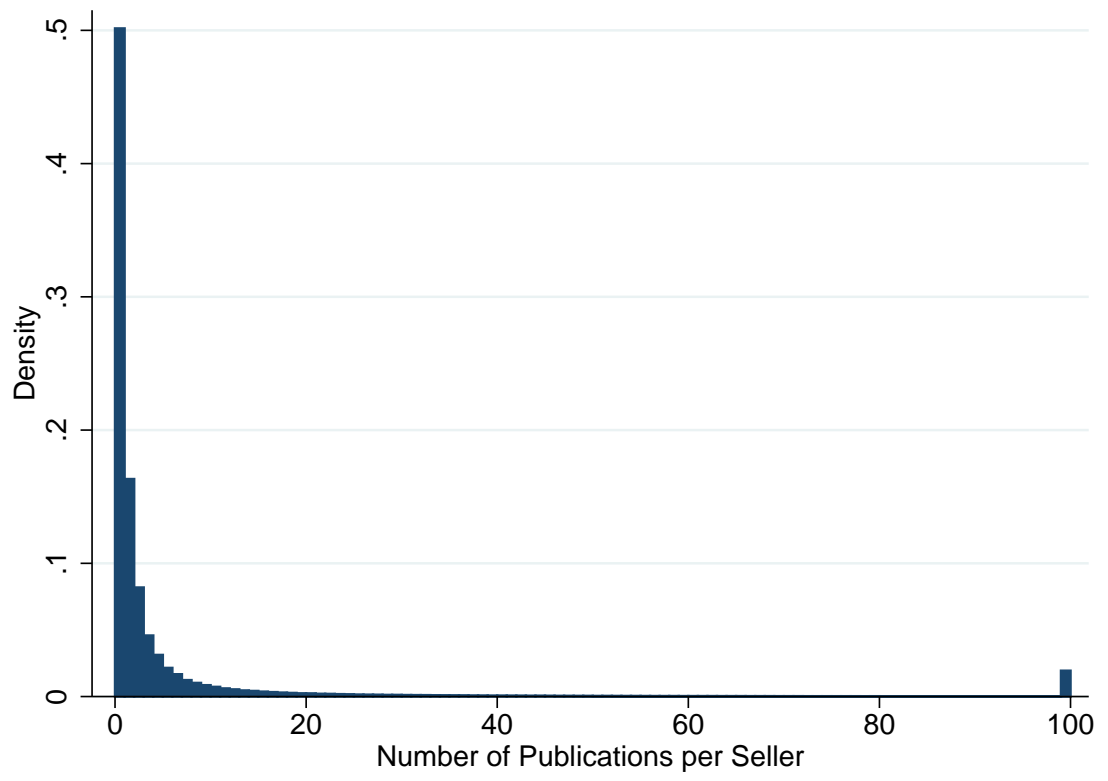

Figure A.4. Changes in the Composition of Goods Sold over Time
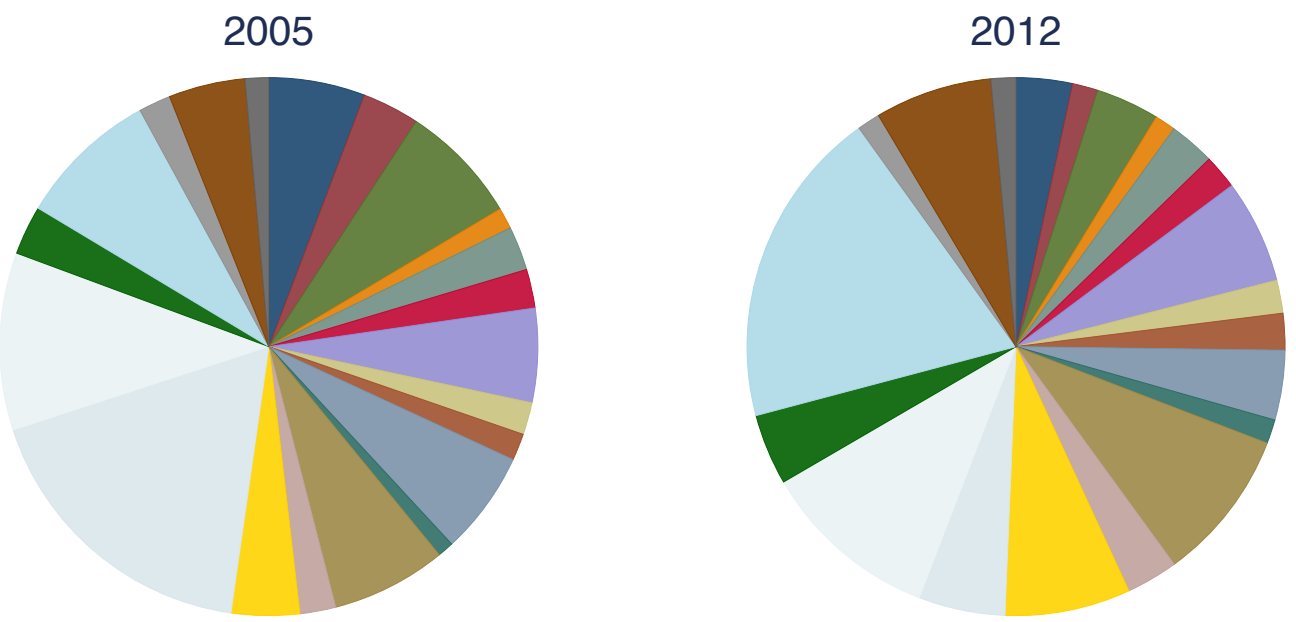

\begin{tabular}{|l|l|l|}
\hline Electronics/Audio/Video & Cameras & Phones \\
\hline Pets & Games/Toys & Videogames \\
\hline Music/Movies & Music Instruments & Health/Beauty \\
Sports & Baby & Clothing \\
\hline Industries/Office & Home/Furniture/Garden & Computers \\
Hobbies & Other & Books and Comics \\
Jewelry & Car Acc. & Appliances \\
\hline
\end{tabular}




\section{Appendix B. Theoretical Appendix}

\section{B.1. Complete Characterization of $p_{i t}$}

The firm's $i$ optimal (log) price is fully characterized by

$$
\begin{aligned}
p_{i t} & =\frac{1}{1+\theta\left(\frac{1}{\alpha}-1\right)}\left\{\log \left(\frac{\theta}{\alpha(\theta-1)}\right)+\log (\kappa)\left(\frac{1}{\alpha \gamma}-\frac{1}{\gamma}+1\right)+\frac{\operatorname{var}\left(A \mid \mathcal{I}_{i t}\right)}{2}-\frac{\operatorname{var}\left(B \mid \mathcal{I}_{i t}\right)}{2}\right\} \\
& +\frac{1}{1+\theta\left(\frac{1}{\alpha}-1\right)} \mathbb{E}_{i t}\left[\left(\frac{1}{\alpha}-1\right) \psi_{i t}+\phi_{i t}\right]+\mathbb{E}_{i t}\left[m_{t}\right]+\frac{\left(\theta-\frac{1}{\gamma}\right)\left(\frac{1}{\alpha}-1\right)}{1+\theta\left(\frac{1}{\alpha}-1\right)} \mathbb{E}_{i t}\left[p_{t}-m_{t}\right]
\end{aligned}
$$

where

$$
\begin{gathered}
A \equiv \phi_{i t}+\frac{1}{\alpha}\left(\psi_{i t}+\frac{1}{\gamma}\left(\log (\kappa)+m_{t}\right)+\left(\theta-\frac{1}{\gamma}\right) p_{t}\right) \\
B \equiv \psi_{i t}+\left(\frac{1}{\gamma}-1\right)\left(\log (\kappa)+m_{t}\right)+\left(\theta-\frac{1}{\gamma}\right) p_{t}
\end{gathered}
$$

Similarly, the complete definition of $p_{t}$ is given by

$$
\begin{aligned}
p_{t} & =\log P_{t}=\frac{1}{1-\theta} \log \left(\int_{0}^{1} \Psi_{i t} P_{i t}^{1-\theta} \mathrm{d} i\right) \\
& =\frac{1}{2(1-\theta)}\left(\operatorname{var}^{i}\left(\psi_{i t}\right)+(1-\theta)^{2} \operatorname{var}^{i}\left(p_{i t}\right)+2(1-\theta) \operatorname{cov}\left(\psi_{i t}, p_{i t}\right)\right)+\int_{0}^{1} p_{i t} \mathrm{~d} i
\end{aligned}
$$

where

$$
\begin{aligned}
\operatorname{cov}\left(\psi_{i t}, p_{i t}\right) & =\operatorname{cov}\left(\rho_{\psi}^{T+1} \psi_{i t-T-1}+\sigma_{\psi}\left(\sum_{s=0}^{T} \rho_{\psi}^{s} \varepsilon_{i t-s}^{\psi}\right), p_{i t}\right) \\
& =\rho_{\psi}^{2(T+1)} \frac{1}{1+\theta\left(\frac{1}{\alpha}-1\right)}\left(\frac{1}{\alpha}-1\right)\left(\frac{\sigma_{\psi}^{2}}{1-\rho_{\psi}^{2}}\right) \\
& +\sigma_{\psi} \rho_{\psi}\left[\rho_{\psi}^{0} \ldots \rho_{\psi}^{T-1}\right] \Delta_{3}^{\prime} \Omega^{\prime} \\
\operatorname{cov}\left(\phi_{i t}, p_{i t}\right) & =\operatorname{cov}\left(\rho_{\phi}^{T+1} \phi_{i t-T-1}+\sigma_{\phi}\left(\sum_{s=0}^{T} \rho_{\phi}^{s} \varepsilon_{i t-s}^{\phi}\right), p_{i t}\right) \\
& =\rho_{\phi}^{2(T+1)} \frac{1}{1+\theta\left(\frac{1}{\alpha}-1\right)}\left(\frac{\sigma_{\phi}^{2}}{1-\rho_{\phi}^{2}}\right) \\
& +\sigma_{\phi} \rho_{\phi}\left[\rho_{\phi}^{0} \ldots \rho_{\phi}^{T-1}\right] \Delta_{4}^{\prime} \Omega^{\prime}
\end{aligned}
$$


The expressions for the common knowledge components of $p_{i t}$ and $p_{t}$ are given by

$$
\begin{aligned}
\hat{p}_{i t} & =\frac{1}{1+\frac{1}{\gamma}\left(\frac{1}{\alpha}-1\right)}\left\{\log \left(\frac{\theta}{\alpha(\theta-1)}\right)+\log (\kappa)\left(\frac{1}{\alpha \gamma}-\frac{1}{\gamma}+1\right)+\frac{\operatorname{var}\left(A \mid \mathcal{I}_{i t}\right)}{2}-\frac{\operatorname{var}\left(B \mid \mathcal{I}_{i t}\right)}{2}\right\} \\
& +\frac{1}{2(1-\theta)}\left(\operatorname{var}^{i}\left(\psi_{i t}\right)+(1-\theta)^{2} \operatorname{var}^{i}\left(p_{i t}\right)+2(1-\theta) \operatorname{cov}\left(\psi_{i t}, p_{i t}\right)\right) \frac{\left(\theta-\frac{1}{\gamma}\right)\left(\frac{1}{\alpha}-1\right)}{1+\frac{1}{\gamma}\left(\frac{1}{\alpha}-1\right)} \\
& +m_{t-T-1}+(T+1) \mu+\frac{1}{1+\theta\left(\frac{1}{\alpha}-1\right)}\left(\left(\frac{1}{\alpha}-1\right) \rho_{\psi}^{T+1} \psi_{i t-T-1}+\rho_{\phi}^{T+1} \phi_{i t-T-1}\right)
\end{aligned}
$$

and

$$
\begin{aligned}
\hat{p}_{t} & =\frac{1}{1+\frac{1}{\gamma}\left(\frac{1}{\alpha}-1\right)}\left\{\log \left(\frac{\theta}{\alpha(\theta-1)}\right)+\log (\kappa)\left(\frac{1}{\alpha \gamma}-\frac{1}{\gamma}+1\right)+\int_{0}^{1} \frac{\operatorname{var}\left(A \mid \mathcal{I}_{i t}\right)}{2}-\frac{\operatorname{var}\left(B \mid \mathcal{I}_{i t}\right)}{2} \mathrm{~d} i\right\} \\
& +\frac{1}{2(1-\theta)}\left(\operatorname{var}^{i}\left(\psi_{i t}\right)+(1-\theta)^{2} \operatorname{var}^{i}\left(p_{i t}\right)+2(1-\theta) \operatorname{cov}\left(\psi_{i t}, p_{i t}\right)\right)\left(\frac{\left(\theta-\frac{1}{\gamma}\right)\left(\frac{1}{\alpha}-1\right)}{1+\frac{1}{\gamma}\left(\frac{1}{\alpha}-1\right)}+1\right) \\
& +m_{t-T-1}+(T+1) \mu
\end{aligned}
$$

, respectively. Note that the two terms in the integral will not vary across firms. In particular the terms $\operatorname{var}\left(A \mid \mathcal{I}_{i t}\right), \operatorname{var}\left(B \mid \mathcal{I}_{i t}\right)$ are the same for all firms in spite of the fact that firms' filtrations may vary depending on the realizations of their own idiosyncratic signals. The reason is that idiosyncratic signals affect the conditional mean of shocks but not the conditional variance. However, we still compute these expressions because they will be used for welfare analysis. Then, using the fact that the variance of the common knowledge component conditional on the common knowledge component is zero,

$$
\begin{aligned}
\operatorname{var}\left(A \mid \mathcal{I}_{i t}\right) & =\operatorname{var}\left\{\sigma_{\Phi} \varepsilon_{i t}^{\phi}+\sigma_{\Phi} \rho_{\Phi} \boldsymbol{\Upsilon}_{\boldsymbol{\Phi}} \varepsilon_{\boldsymbol{i t}}^{\boldsymbol{\phi}}+\frac{1}{\alpha}\left(\sigma_{\Psi} \varepsilon_{i t}^{\psi}+\sigma_{\Psi} \rho_{\Psi} \boldsymbol{\Upsilon}_{\boldsymbol{\Psi}} \varepsilon_{\boldsymbol{i t}}^{\boldsymbol{\psi}}\right)\right. \\
& \left.+\frac{1}{\alpha}\left(\frac{1}{\gamma} \sigma_{m} \mathbf{1} \varepsilon_{t}^{m}+\frac{1}{\gamma} \sigma_{m} \varepsilon_{t}^{m}+\left(\theta-\frac{1}{\gamma}\right)\left(\sigma_{m} k^{m} \varepsilon_{t}^{m}+\sigma_{p} k^{p} \varepsilon_{t}^{p}\right)\right) \mid \mathcal{I}_{i t}\right\} \\
& =\sigma_{\Phi}^{2}+\frac{\sigma_{\Psi}^{2}}{\alpha^{2}}+\frac{\sigma_{m}^{2}}{\alpha^{2} \gamma^{2}}+\operatorname{var}\left(\Delta_{\Sigma}^{1}\left[\begin{array}{llll}
\varepsilon_{t}^{m} & \varepsilon_{t}^{p} & \varepsilon_{i t}^{\psi} & \boldsymbol{\varepsilon}_{i t}^{\phi}
\end{array}\right]^{\prime} \mid \mathcal{I}_{i t}\right) \\
& =\sigma_{\Phi}^{2}+\frac{\sigma_{\Psi}^{2}}{\alpha^{2}}+\frac{\sigma_{m}^{2}}{\alpha^{2} \gamma^{2}}+\Delta_{\Sigma}^{1} \operatorname{var}\left(\left[\begin{array}{llll}
\varepsilon_{t}^{m} & \varepsilon_{t}^{p} & \varepsilon_{i t}^{\psi} & \boldsymbol{\varepsilon}_{i t}^{\phi}
\end{array}\right]^{\prime} \mid \mathcal{I}_{i t}\right) \Delta_{\Sigma}^{1^{\prime}}
\end{aligned}
$$

where

$$
\Delta_{\Sigma}^{1} \equiv\left[\frac{1}{\alpha}\left(\frac{1}{\gamma} \mathbf{1}+\left(\theta-\frac{1}{\gamma}\right) k^{m}\right) \sigma_{m} \quad \frac{1}{\alpha}\left(\theta-\frac{1}{\gamma}\right) \sigma_{p} k^{p} \quad \frac{\sigma_{\Psi} \rho_{\Psi} \Upsilon_{\Psi}}{\alpha} \quad \sigma_{\Phi} \rho_{\Phi} \Upsilon_{\boldsymbol{\Phi}}\right]
$$


and

$$
\begin{aligned}
\operatorname{var}\left(B \mid \mathcal{I}_{i t}\right) & =\operatorname{var}\left\{\sigma_{\Psi} \varepsilon_{i t}^{\psi}+\sigma_{\Psi} \rho_{\Psi} \boldsymbol{\Upsilon}_{\boldsymbol{\Psi}} \boldsymbol{\varepsilon}_{\boldsymbol{i t}}^{\boldsymbol{\psi}}+\left(\frac{1}{\gamma}-1\right)\left(\sigma_{m} \mathbf{1} \boldsymbol{\varepsilon}_{t}^{m}+\sigma_{m} \varepsilon_{t}^{m}\right)\right. \\
& \left.+\left(\theta-\frac{1}{\gamma}\right)\left(\sigma_{m} k^{m} \varepsilon_{t}^{m}+\sigma_{p} k^{p} \boldsymbol{\varepsilon}_{t}^{p}\right) \mid \mathcal{I}_{i t}\right\} \\
& =\sigma_{\Psi}^{2}+\left(\frac{1}{\gamma}-1\right)^{2} \sigma_{m}^{2}+\Delta_{\Sigma}^{2} \operatorname{var}\left(\left[\begin{array}{llll}
\boldsymbol{\varepsilon}_{t}^{m} & \boldsymbol{\varepsilon}_{t}^{p} & \boldsymbol{\varepsilon}_{i t}^{\psi} & \boldsymbol{\varepsilon}_{i t}^{\phi}
\end{array}\right]^{\prime} \mid \mathcal{I}_{i t}\right) \Delta_{\Sigma}^{2^{\prime}}
\end{aligned}
$$

where

$$
\Delta_{\Sigma}^{2} \equiv\left[\left(\left(\frac{1}{\gamma}-1\right) \mathbf{1}+\left(\theta-\frac{1}{\gamma}\right) k^{m}\right) \sigma_{m} \quad\left(\begin{array}{lll}
\left.\theta-\frac{1}{\gamma}\right) \sigma_{p} k^{p} & \sigma_{\Psi} \rho_{\Psi} \Upsilon_{\boldsymbol{\Psi}} & \mathbf{0}
\end{array}\right]\right.
$$

Finally,

$$
\left.\operatorname{var}\left[\begin{array}{c}
\varepsilon_{t}^{m} \\
\varepsilon_{t}^{p} \\
\varepsilon_{i t}^{\psi} \\
\varepsilon_{i t}^{\phi}
\end{array}\right] \mathcal{I}_{i t}\right]=\left[\begin{array}{llll}
I & 0 & 0 & 0 \\
0 & I & 0 & 0 \\
0 & 0 & I & 0 \\
0 & 0 & 0 & I
\end{array}\right]-\left[\begin{array}{c}
\Delta_{1}^{\prime} \\
\Delta_{2}^{\prime} \\
\Delta_{3}^{\prime} \\
\Delta_{4}^{\prime}
\end{array}\right] \Delta^{-1}\left[\begin{array}{llll}
\Delta_{1} & \Delta_{2} & \Delta_{3} & \Delta_{4}
\end{array}\right]
$$

\section{B.2. Transitional Dynamics}

Here we briefly describe how we transform our baseline model to compute transition dynamics from a state of low uncertainty about the aggregate price level to a state of high uncertainty. Consider a period $t$ such that in $t-j$ there was an anticipated and permanent change in $\sigma_{p}$ (with $j \in\{1, \ldots, T\}$ ). Let $\sigma_{p}^{H}$ be the new and $\sigma_{p}^{L}$ be the old variance of the noise component of the aggregate signal about $p_{t}$. Our new conjecture of the solution of the model is:

$$
p_{t}=\hat{p}_{t}+\sigma_{m} k^{m} \varepsilon_{t}^{m}+k^{p} \operatorname{diag}\left(\sigma_{p j}\right) \varepsilon_{t}^{p}
$$

where

$$
\sigma_{p j}=\left[\begin{array}{c}
\sigma_{p}^{H} \\
\vdots \\
\sigma_{p}^{H} \\
\sigma_{p}^{L} \\
\vdots \\
j+1 \\
\sigma_{p}^{L}
\end{array}\right] \begin{gathered}
1 \\
T
\end{gathered}
$$

The solution is computed similarly as in the baseline case by computing the values of $k^{m}$ and $k^{p}$ that are consistent with this equation and the firms' optimal pricing strategies. 